\title{
Hollow microstructural regulation of single-atom catalysts for optimized electrocatalytic performance
}

\author{
A-Wu Zhou, Ding-Sheng Wang, Ya-Dong Li \\ Department of Chemistry, Tsinghua University, Beijing 100084, China. \\ Correspondence to: Prof. Dingsheng Wang, Department of Chemistry, Tsinghua University, Beijing 100084, China. \\ E-mail: wangdingsheng@mail.tsinghua.edu.cn
}

How to cite this article: Zhou AW, Wang DS, Li YD. Hollow microstructural regulation of single-atom catalysts for optimized electrocatalytic performance. Microstructures 2022;2:2022005. https://dx.doi.org/10.20517/microstructures.2021.08

Received: 9 Sep 2021 First Decision: 14 Oct 2021 Revised: 21 Oct 2021 Accepted: 8 Nov 2021 Published: 17 Jan 2022

Academic Editors: Shujun Zhang, Lianzhou Wang Copy Editor: Yue-Yue Zhang Production Editor: Yue-Yue Zhang

\begin{abstract}
Single-atom catalysts (SACs) and hollow microstructured materials have recently undergone significant advancements in the field of catalysis. The combination of SACs and hollow microstructured materials can further endow them with extraordinary characteristics, such as high loadings, uniform active sites and unique metalsupport interactions and electronic structures. In this review, we focus on the design and construction of SACs supported on hollow microstructured materials for enhancing electrocatalytic reactions. Due to these unique hollow microstructures, most of the active sites can be fully exposed in catalysis. Therefore, the atomic utilization rate is greatly improved. Furthermore, the synergistic effect of SACs and hollow microstructured supports can bring about unpredictable characteristics. The hollow microstructures not only adjust the geometry and electronic structure of the SACs to improve their activity but the SACs can also serve as an auxiliary stimulus to the intrinsic activity of the support to achieve better performance. Compared with the reported traditional dual atomic catalysts, hollow microstructures are conducive for the isolation of atomically dispersed binary atom active sites on both sides of the particle shell. Combined with the current development status, we summarize the challenges and prospects in this area. This review is conducive to the reasonable design and manufacture of advanced SACs supported on hollow materials and the promotion of their future industrial usage in energy applications.
\end{abstract}

Keywords: Microstructures, single-atom catalysts, hollow structures, electrocatalytic activity, energy conversion

(C) The Author(s) 2022. Open Access This article is licensed under a Creative Commons Attribution 4.0 International License (https://creativecommons.org/licenses/by/4.0/), which permits unrestricted use, sharing adaptation, distribution and reproduction in any medium or format, for any purpose, even commercially, as long as you give appropriate credit to the original author(s) and the source, provide a link to the Creative Commons license, and indicate if changes were made. 


\section{INTRODUCTION}

As the energy crisis and environmental problems intensify, it is necessary to rapidly develop sustainable and clean energy sources ${ }^{[1-9]}$. Among the wide variety of proposed technologies, electrochemical energy transformation technologies, such as water splitting, $\mathrm{CO}_{2}$ reduction, fuel cells and metal-air batteries, are considered to be among the most effective substitutes for traditional fossil energy ${ }^{[10-18]}$. Previously reported electrocatalysts have shown high activity and superior stability, most of which are composed of precious transition-metal nanoparticles (NPs), such as $\mathrm{Pt} / \mathrm{C}, \mathrm{RuO}_{2}$ and $\mathrm{IrO}_{2}{ }^{[19-2]}$. However, these precious metalbased catalysts have high costs and scarce reserves, which severely restrict their large-scale application ${ }^{[2-31]}$. Therefore, it is necessary to develop advanced catalysts to reduce catalyst usage without sacrificing the catalytic performance.

Hollow structures are types of functional nanomaterials with cavities or void spaces inside a defined shell ${ }^{[32]}$. Due to their unique structural characteristics and physical and chemical properties, advanced hollow structures exhibit some functions that simple NPs cannot obtain, especially in heterogeneous catalysis. Compared with their solid counterparts, hollow structures have several advantages. They effectively isolate the catalytic material and stabilize the NPs to prevent sintering. They can achieve cascade reactions by regulating the spatial position of catalytically active sites. By precisely controlling the pore size in the shell, the hollow structures improve the selectivity of the catalytic reaction through the difference in molecular sieve or nanopore diffusivity. In addition, hollow structures are generally suitable for improving mass transfer ${ }^{[33-35]}$.

Metal-based NPs are important heterogeneous catalysts, since they not only have high activity and selectivity for specific chemical reactions but also have good stability under harsh conditions ${ }^{[36]}$. Among the various strategies utilized, the downsizing of metal NP catalysts to the atomic scale, especially precious metal catalysts, is an effective strategy to construct advanced catalyst ${ }^{[37-43]}$. Single-atom catalysts (SACs) have received significant attention because of their maximum utilization of metal atoms and unique electronic structures in heterogeneous and electrochemical reactions ${ }^{[30,44-54]}$.

The design concept of highly dispersed active species as heterogeneous catalysts be traced back to the research of Maschmeyer et al..$^{[55]}$ in 1995 . They found that Ti highly dispersed on mesoporous MCM-41 could be used for the epoxidation of cyclic olefins by grafting organometallic complexes into mesoporous silica ${ }^{[55]}$. In 2003, Fu et al. ${ }^{[56]}$ reported an ionic Au-cerium oxide catalyst for the water-gas shift reaction without Au particles. They demonstrated that the metal NPs were not active for the water-gas shift reaction. In 2007, Hackett et al. ${ }^{[57]}$ reported the use of atomically dispersed $\mathrm{Pd}^{\mathrm{II}}$ supported on mesoporous $\mathrm{Al}_{2} \mathrm{O}_{3}$ for the selective aerobic oxidation of allylic alcohols. In 2011, Qiao et al. ${ }^{[39]}$ proposed the concept of SACs for the first time, which has attracted significant attention in the field of catalysis. They reported single Pt atoms dispersed on $\mathrm{FeO}_{x}$ with high $\mathrm{CO}$ oxidation activity. In 2016, Yin et al. ${ }^{[58]}$ made a major breakthrough in the preparation of high-loaded SACs (4 wt.\%), which opened up new avenues for the general synthesis of various SACs.

Compared with conventional catalysts, SACs fully expose every atom as a catalytic site, which maximizes the atomic efficiency of metals and minimizes the amount of precious metals. SACs have the advantages of heterogeneous and homogeneous catalysts and bridge the gap between heterogeneous and homogeneous catalysts ${ }^{[5]}$. SACs can realize the rational use of metal resources and promote atomic economy by maximizing the efficiency of atom utilization ${ }^{[60,61]}$. Due to their quantum size and structural effects and strong metal-support interactions, SACs have additional advantages. In addition, the unique electronic structure and unsaturated coordination environment of the active sites in SAC can significantly improve the 
catalytic performance ${ }^{[2-66]}$. Moreover, SACs with uniform metal active sites are beneficial to the study of electrocatalytic mechanisms ${ }^{[67-70]}$.

A large number of reviews have focused on the influence of geometric and electronic structure regulations on the catalytic performances of SACs ${ }^{[38,71-77]}$. In contrast, relatively few reviews have discussed the relationship between SACs supported by hollow microstructures and catalytic activity. The catalytic properties of SACs rely on the characteristics of the active sites and their accessibility to reactants, which are greatly affected by the hollow microstructures of the supports. Hollow structured materials as SAC supports have several unique features, including high surface area, low density and high loading capacity, for catalysis ${ }^{[33,78-81]}$. Compared with bulk materials supporting SACs, confined SACs can be directly exposed as active sites on hollow microstructured supports, thus ensuring 100\% exposure of single atoms to reactants. Cascade reactions can be achieved by placing SACs on hollow microstructures with controllable spatial localization. Hollow microstructures with thin shells provide more expedited mass-transfer processes. Finally, the thin shells in hollow structures enhance catalytic selectivity.

This review focuses on the design and construction of SACs supported on hollow microstructured materials for enhancing electrocatalytic reactions. Recent configurations of hollow microstructures supporting SACs can be divided into three types, namely, single-shell hollow, core-shell and yolk-shell structures [Figure 1]. The accessibility of SACs in hollow microstructures and their performance in mass diffusion are highlighted. In addition, the research progress of SACs supported on hollow microstructures in electrocatalysis and their advantages/disadvantages in electrocatalysis are discussed. Moreover, we emphasize the importance and challenges in the rational design of hollow microstructured catalysts in electrocatalytic reactions, which have excellent potential for applications in energy conversion.

\section{A HOLLOW MICROSTRUCTURAL MODULATION STRATEGY FOR SACS}

The accessibility and nature of single atomic sites are significantly affected by the microstructures of the catalysts, including their morphology, size, shape and surface structure ${ }^{[35,82,83]}$. As a special type of microstructure, hollow microstructures have attracted particular attention ${ }^{[8,84-86]}$. Compared with solid materials, hollow microstructures not only greatly increase the specific surface area of catalysts to expose the active sites but also facilitate the diffusion of the substrate ${ }^{[82,87-89]}$. Therefore, the regulation of hollow microstructures can remarkably affect and even manipulate the catalytic performance of SACs ${ }^{[8,909-93]}$. Herein, we focus on studying the methods, intrinsic properties and regulation of hollow microstructures to improve the electrocatalytic performance.

\section{SACs supported on single-shell hollow materials}

Single-shell hollow microstructures have empty spaces inside a single shell. The physicochemical properties of hollow microstructures can be modulated via a series of parameters, including external shape, internal configuration and shell architecture ${ }^{[81]}$. The shell composition of hollow microstructures has changed from carbon species (or metal oxides) to multiple compounds, such as metal-organic frameworks (MOFs), in recent years. Many strategies for the successful synthesis of hollow microstructures have been reported. Hollow microstructures with internal voids can effectively improve the weight fraction and mass activity of SACs. In addition, hollow structures provide more accessible areas to expose the active sites of SACs in catalysis $^{[84-89]}$.

Recently, MOFs composed of metal ions/clusters and functionalized organic linkers have been investigated as ideal supports for anchoring SACs ${ }^{[25,28,3,1,47,94-99]}$. For instance, Liang et al. ${ }^{[100]}$ demonstrated a strategy for preparing isolated Fe atomic sites anchored in hollow carbon polyhedra (Fe-SAs/NPS-HC) derived from 

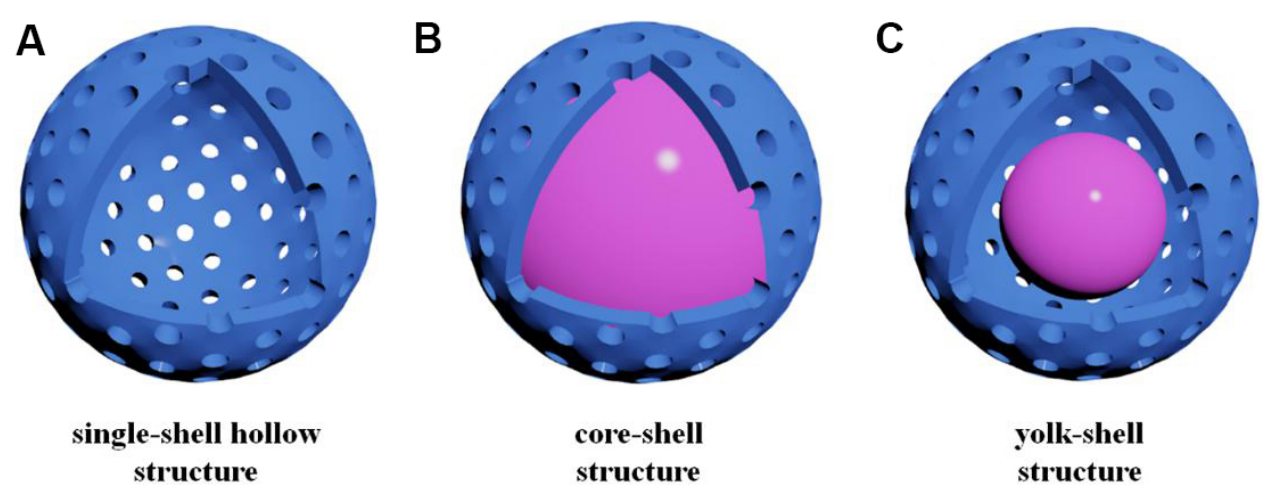

Figure 1. Schematic illustration of (A) single-shell hollow, (B) core-shell and (C) yolk-shell structures.

MOF@polymer composites via the Kirkendall effect [Figure 2A]. A series of controlled experiments proved that sulfur plays a significant role in the construction of single-shell hollow microstructures. The uniform single-shell hollow morphology of Fe-SAs/NPS-HC was identified by transmission electron microscopy (TEM) and high-angle annular dark field scanning TEM (HAADF-STEM), with a shell thickness of $\sim 20 \mathrm{~nm}$ [Figure $2 \mathrm{~B}$ ]. In addition, energy-dispersive spectroscopy mappings proved the uniform spatial distribution of iron, carbon, nitrogen, phosphorus and sulfur throughout the hollow shell. Furthermore, aberrationcorrected HAADF-STEM (AC HAADF-STEM) and XANES analysis directly confirmed the atomic dispersion of Fe [Figure $2 \mathrm{C}-\mathrm{E}$ ]. Due to the structure function and electronic control of Fe SACs, the catalysts exhibit significant oxygen reduction reaction (ORR) performance in both alkaline and acid media [Figure $2 \mathrm{~F}$ and $\mathrm{G}$ ].

Similarly, Chen et al. ${ }^{[101]}$ also constructed unique Co SACs supported on hollow carbon polyhedra $\left(\mathrm{Co}_{1}-\mathrm{N}_{3}\right.$ $\mathrm{PS} / \mathrm{HC}$ ). The synergistic coordination of $\mathrm{N}, \mathrm{P}$ and $\mathrm{S}$ atoms was introduced into the single-shell hollow carbon polyhedra to adjust and optimize the electronic density of Co SAC active centers and construct novel optimal Co- $\mathrm{N}_{3} \mathrm{PS}$ active configurations. $\mathrm{Co}_{1}-\mathrm{N}_{3} \mathrm{PS} / \mathrm{HC}$ exhibits an efficient ORR reactivity $\left(176 \mathrm{~mW} \mathrm{~cm}^{-2}\right.$ at a current density of $\left.280 \mathrm{~mA} \mathrm{~cm}^{-2}\right)$ better than commercial $\mathrm{Pt} / \mathrm{C}\left(117 \mathrm{~mW} \mathrm{~cm}{ }^{-2}\right)$, significant ORR kinetics and excellent stability in both alkaline and acid media. Furthermore, a Zn-air battery based on $\mathrm{Co}_{1}-\mathrm{N}_{3} \mathrm{PS} / \mathrm{HC}$ showed outstanding battery performance $\left(786 \mathrm{mAh} \mathrm{g}^{-1}\right.$ at $\left.10 \mathrm{~mA} \mathrm{~cm}{ }^{-2}\right)$ and long-term charge/discharge durability. Moreover, they used the same method to synthesize a single-atom Ir catalyst on a single-shell hollow carbon substrate ${ }^{[78]}$. It was shown that the designed hollow structure plays an important role in accelerating the kinetics and improving performance. He et al. ${ }^{[102]}$ synthesized a series of noble-metal ( $\mathrm{Ir}, \mathrm{Pt}, \mathrm{Ru}, \mathrm{Au}$ and $\mathrm{Pd}$ ) single atoms immobilized on hollow nanotubes derived from a zirconiumporphyrinic MOF, which are equipped with square-planar four coordinate porphyrin units to anchor a single atom. This unique single-shell hollow structure was beneficial for fast mass diffusion.

Yang et al.$^{[103]}$ reported a solid phase thermal diffusion approach to prepare Mn isolated single-atom site catalysts on $\mathrm{N}$-doped carbon nanotubes by the pyrolysis of a $\mathrm{MnO}_{2}$ nanowires@ZIF-8 core-shell structure. After $\mathrm{NH}_{3}$ treatment, the Mn SAs- $\mathrm{N}_{2}$ coordination sites were controllably transformed into Mn SAs- $\mathrm{N}_{4}$ coordination sites. This method generally uses acids and bases to etch the template, which may damage the composition and structure of the nanomaterial. Wang et al. ${ }^{[104]}$ constructed single Fe atom catalysts supported on $\mathrm{N}$-doped hollow carbon nanocages by the pyrolysis of ZIF- 8 and pyrrole. As more single Fe atom active sites are exposed in the hollow carbon structure, the obtained Fe-ISAs/H-CN catalysts show high-efficiency activity in alkaline solutions. The typical ZIF-8 has been widely used to construct M-NC catalysts. Unfortunately, the resulting dense carbon framework hinders mass transfer and blocks many 
A
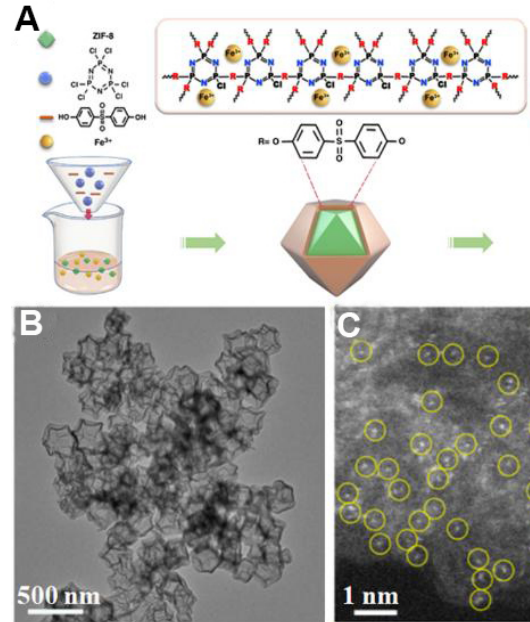
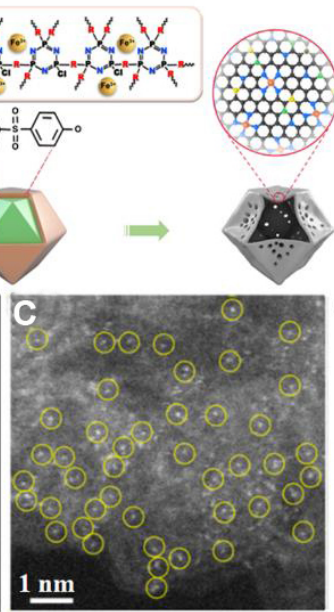

D
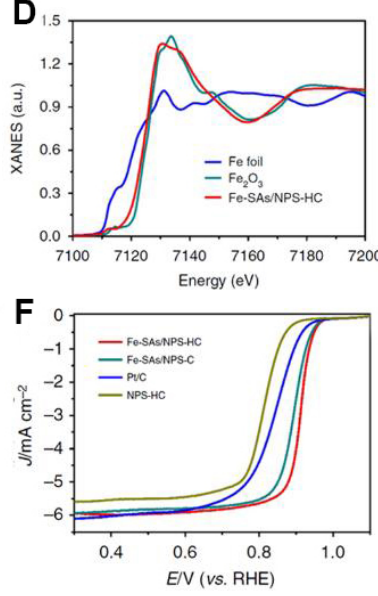

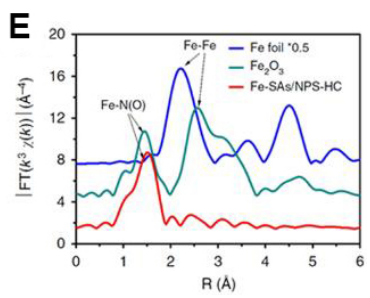

G

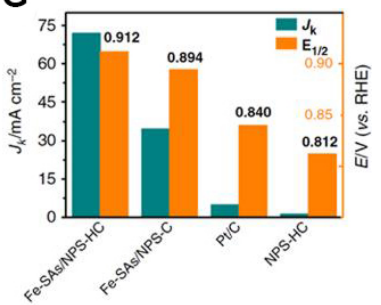

Figure 2. (A) Illustration of the synthetic strategy of Fe-SAs/NPS-HC. (B) TEM and (C) AC HAADF-STEM images of Fe-SAs/NPS-HC. (D) Fe K-edge XANES and (E) Fe K-edge $\mathrm{k}_{3}$-weighted Fourier transform (FT) spectra of Fe-SAs/NPS-HC, $\mathrm{Fe}_{2} \mathrm{O}_{3}$ and Fe foil. (F) ORR polarization curves, (G) $\mathrm{J}_{\mathrm{k}}$ at $0.85 \mathrm{~V}$ and $\mathrm{E}_{1 / 2}$ of Fe-SAs/NPS-HC, Fe-SAs/NPS-C and NPS-HC ${ }^{[100]}$. TEM: Transmission electron microscopy; HAADF-STEM: high angle annular dark field scanning TEM; ORR: oxygen reduction reaction.

metal sites. Li et al ${ }^{[105]}$ proposed a dual-linker zeolitic tetrazolate framework-engaged strategy to prepare single $\mathrm{Ni}$ atom catalysts supported on hollow plates. 5-Aminotetrazole was used as a self-sacrificing template and 2-methylimidazole was mainly used as a carbon and nitrogen source to form a hollow N-rich carbon matrix. The hollow structure of the obtained catalysts had more mesoporosity and available surface area, which promote mass transfer and provide abundant single Ni sites that are beneficial to enhancing the catalytic performance for electrochemical $\mathrm{CO}_{2}$ reduction with high selectivity $(\sim 100 \%)$ to $\mathrm{CO}$.

The synergistic effect based on the interface of binary atom sites provides a unique perspective for understanding the reaction mechanism in the electrocatalytic process ${ }^{[106]}$. Han et al ${ }^{[107]}$ reported atomically dispersed binary Co-Ni sites supported in N-doped single-shell hollow carbon cubes (CoNi-SAs/NC) by the pyrolysis of CoNi-MOFs [Figure 3]. Such single-shell hollow carbon generates high surface areas and abundant mesopores, which shorten the paths for ionic/electronic diffusion and provide effective mass transfer channels. Benefiting from the abundant single-atom active sites and the synergistic effect of Co-Ni sites, the resultant CoNi-SAs/NC catalysts provide a low overpotential, high electron transfer number and good reversibility in alkaline electrolytes. Density functional theory results revealed that the ratedetermining step (RDS) on single-shell hollow $\mathrm{NC}$ and $\mathrm{Ni}-\mathrm{N}$ is the hydrogenation of molecular $\mathrm{O}_{2}$, while the RDS on Co-Ni-N becomes the protonation of $\mathrm{OH}^{*}$, thereby highlighting the critical role of bimetallic $\mathrm{Co} / \mathrm{Ni}$ sites in energetically facilitating the ORR process. Furthermore, they emphasize the accessibility of SACs with high activity and the synergistic interaction of Co-Ni-N in reducing the energy barrier and improving the reaction kinetics. Deng et al. ${ }^{[108]}$ used a hollow ZIF-8 precursor to prepare N-doped hollow carbon polyhedra implanted with single Fe atoms (C-FeHZ @g- $\left.\mathrm{C}_{3} \mathrm{~N}_{4}\right)$. The obtained FeHZ $\mathrm{Z}_{8} @ g-\mathrm{C}_{3} \mathrm{~N}_{4}$ catalysts possessed an exclusively high density of $\mathrm{Fe}-\mathrm{N}_{4}$ sites and exhibited excellent ORR activity with a half-wave potential of $0.78 \mathrm{~V}$ in an acidic medium and $0.845 \mathrm{~V}$ in an alkaline medium. In addition, the catalysts display remarkable performance in $\mathrm{H}_{2} / \mathrm{O}_{2}$ proton exchange membrane fuel cells.

Due to their large-scale preparation and high uniformity, $\mathrm{SiO}_{2}$ materials as physical scaffolds are often used as hard templates. In short, the hard template synthesis includes the following steps: (1) preparing a hard template with a specific shape; (2) coating (or depositing) the target material on the template; and (3) removing the internal template. The hard template method is the common and effective method to fabricate 

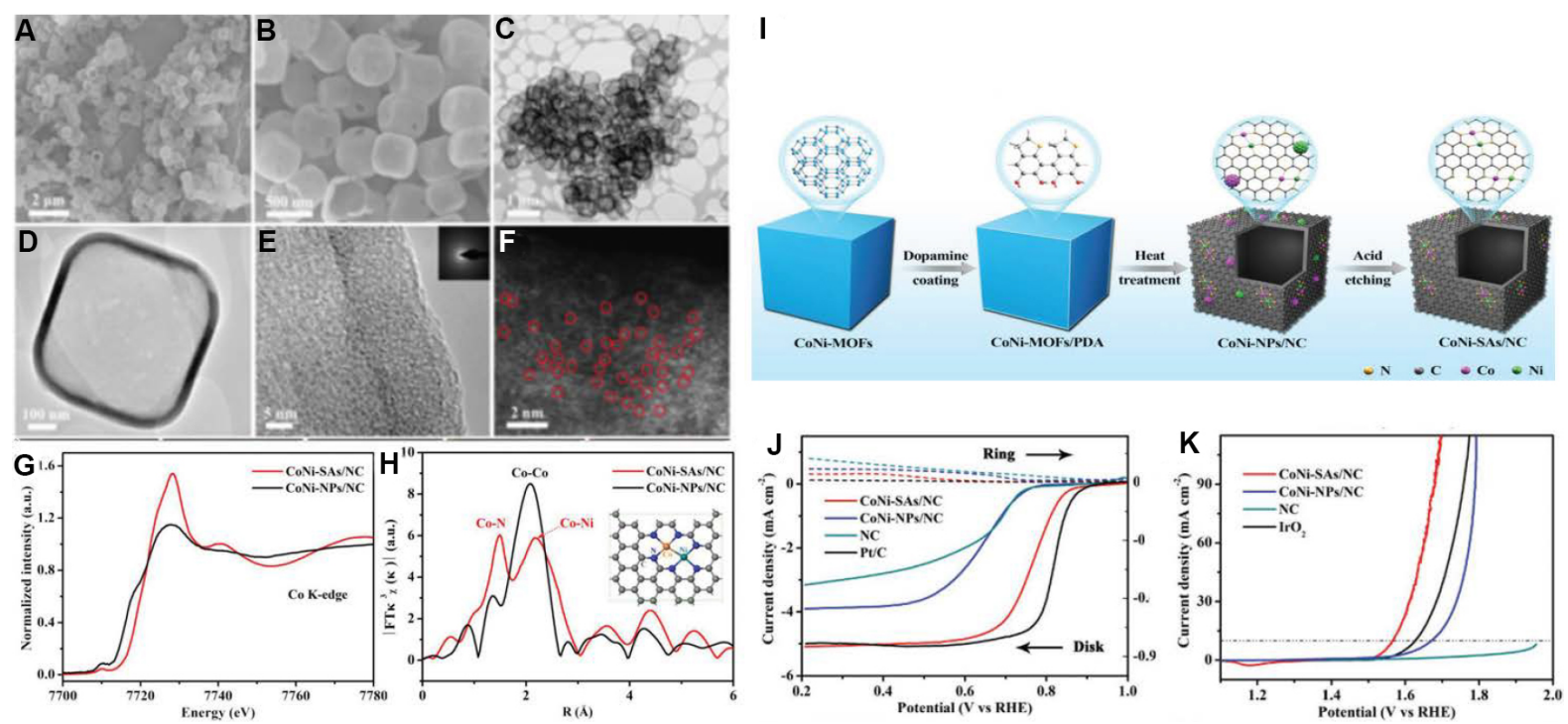

Figure 3. (A, B) SEM, (C, D), TEM, (E) HRTEM and (F) AC HAADF-STEM images of CoNi-SAs/NC. (G) Co K-edge XANES spectra and (H) Fourier transforms of Co K-edge spectra of CoNi-SAs/NC and CoNi-NPs/NC (inset: the model of Ni-Co dual sites). (I) Schematic illustration of the formation of CoNi-SAs/NC. (J) ORR polarization curves and (K) OER polarization curves of CoNi-SAs/NC and reference samples ${ }^{[107]}$. SEM: Scanning electron microscope; HRTEM: high resolution TEM; XANES: X-ray absorption near edge structure; OER: oxygen evolution reaction.

hollow nanostructures loaded with single atoms. Su et al.$^{[109]}$ used silica as a template to construct Fe-N/C and $\mathrm{Fe}-\mathrm{ND} / \mathrm{C}$ on hollow carbon spheres. The Fe-ND/C catalysts with the proposed coordination structure facilitate the desorption of $\mathrm{OH}^{*}$. Kuang et al. ${ }^{[110]}$ prepared $\mathrm{N}$-doped mesoporous hollow carbon spheres loaded with $\mathrm{Pt}$ single atoms ( $\mathrm{Pt}_{1} / \mathrm{NMHCS}$ ) via a $\mathrm{SiO}_{2}$ template strategy. Due to the strong electronic metalsupport interaction between the single-shell hollow carbon support and Pt SACs, the obtained $\mathrm{Pt}_{1} / \mathrm{NMHCS}$ possessed more electron depletion and a higher oxidation state than single Pt atoms. This greatly promoted the outstanding hydrogen evolution reaction activity. $\mathrm{Pt}_{1} / \mathrm{NMHCS}$ exhibits a higher mass activity $\left(2.07 \mathrm{~A} / \mathrm{mg}_{\mathrm{Pt}}\right.$ at a $50 \mathrm{mV}$ overpotential) than that of $\mathrm{Pt}_{\mathrm{NP}} / \mathrm{MHCS}\left(0.89 \mathrm{~A} / \mathrm{mg}_{\mathrm{Pt}}\right)$ and $20 \mathrm{wt} . \% \mathrm{Pt} / \mathrm{C}$ $\left(0.58 \mathrm{~A} / \mathrm{mg}_{\mathrm{Pt}}\right)$.

The reasonable design of cost-effective non-precious metal-based catalysts to substitute Pt in the ORR is ideal for the development of sustainable energy conversion equipment. Recently, transition-metal SACs have become new cutting-edge catalysts with high activity, stability and selectivity, illustrating their remarkable potential for various electrocatalytic applications. For instance, Chen et al. ${ }^{[111]}$ developed a modified hard-templating strategy to prepare SACs supported on functional Janus hollow graphene. As shown in Figure 4A, the surface of the positively charged $\mathrm{SiO}_{2}$ nanospheres first adsorbs the electronegative $\left[\mathrm{Ni}(\mathrm{CN})_{4}\right]^{2-} . \mathrm{SiO}_{2} @\left[\mathrm{Ni}(\mathrm{CN})_{4}\right]^{2-}$ intermediates are then tightly wrapped by graphene oxide (GO) nanosheets. Subsequently, the $\mathrm{Fe}^{2+}$ phthalocyanine (FePc) is adsorbed on the outer surface and then pyrolyzed at $700{ }^{\circ} \mathrm{C}$. Finally, the $\mathrm{SiO}_{2}$ hard template is etched with a $\mathrm{NaOH}$ solution to obtain $\mathrm{Ni}-\mathrm{N}_{4} / \mathrm{GHSs} / \mathrm{Fe}-\mathrm{N}_{4} \cdot \mathrm{Ni}_{-} \mathrm{N}_{4}$ and Fe$\mathrm{N}_{4}$ species are uniformly dispersed on different sides of single-shell hollow graphene [Figure 4]. The combination of experiment and theory proved that the external Fe- $\mathrm{N}_{4}$ and internal Ni- $\mathrm{N}_{4}$ sites in Ni- $\mathrm{N}_{4}$ /GHSs/Fe- $\mathrm{N}_{4}$ are active for the ORR and OER, respectively. Compared with reported traditional dual atomic catalysts, $\mathrm{Ni}-\mathrm{N}_{4} / \mathrm{GHSs} / \mathrm{Fe}-\mathrm{N}_{4}$ catalysts can isolate the active sites of $\mathrm{Fe}-\mathrm{N}_{4}$ and $\mathrm{Ni}-\mathrm{N}_{4}$ to balance the competition between the ORR and OER rate-limiting steps. Due to their dual-function characteristics, Ni$\mathrm{N}_{4} / \mathrm{GHS} / \mathrm{Fe}-\mathrm{N}_{4}$ catalysts exhibit remarkable energy efficiency and cycling stability in rechargeable Zn-air batteries. 

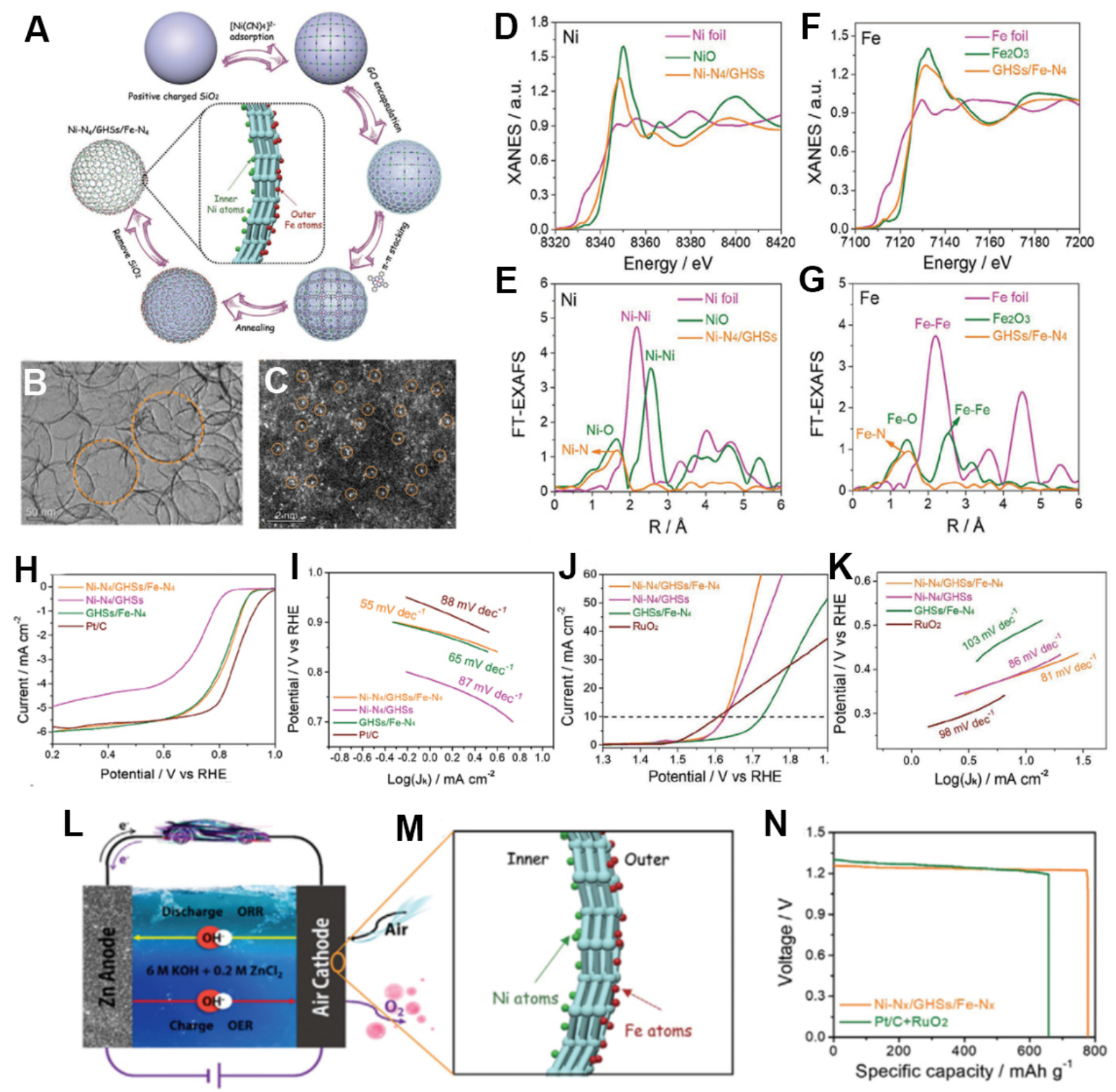

Figure 4. (A) Schematic diagram of the formation of single-shell hollow Ni-N $/$ GHSs/Fe- $N_{4}$. (B) TEM and (C) AC HAADF-STEM

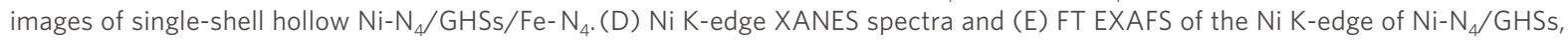
$\mathrm{NiO}$ and Ni foil. (F) Fe K-edge XANES spectra and (G) FT EXAFS of the Fe K-edge of $\mathrm{Fe}_{-} \mathrm{N}_{4} / \mathrm{GHSs}, \mathrm{Fe}_{2} \mathrm{O}_{3}$ and Fe foil. (H) ORR and (J) OER polarization curves in $\mathrm{O}_{2}$-saturated $0.1 \mathrm{M} \mathrm{KOH}$. (I, K) Tafel plots of $\mathrm{Ni}-\mathrm{N}_{4} / \mathrm{GHSs} / \mathrm{Fe}-\mathrm{N}_{4}$ and reference catalyst. (L, M) Schematic diagram and (N) discharge curves of a $\mathrm{Zn}$-air battery assembled with $\mathrm{Ni}-\mathrm{N}_{4} / \mathrm{GHSs} / \mathrm{Fe}^{-} \mathrm{N}_{4}{ }^{[111]}$. TEM: Transmission electron microscopy; AC-HAADF-STEM: aberration-corrected high angle annular dark field scanning transmission electron microscopy; FT: fourier transforms; EXAFS: extended X-ray absorption fine structure; XANES: X-ray absorption near edge structure; ORR: oxygen reduction reaction; OER: oxygen evolution reaction.

Chen et al. ${ }^{[12]}$ also reported a $\mathrm{SiO}_{2}$ template strategy to synthesize single Fe atoms on single-shell hollow Ndoped carbon nanospheres (Fe-N-C HNSs). Benefiting from $\mathrm{Fe}-\mathrm{N}_{4}$ parts and a unique hollow structure with large surface area and high conductivity, the obtained Fe-N-C HNSs have significant ORR performance and high stability in alkaline solutions, as well as excellent methanol resistance. Compared with N-doped carbon hollow nanospheres without single Fe atoms and Fe-N-C samples without hollow nanospheres, the Fe-N-C HNSs emphasized the high activity of SACs and the structural advantages of single-shell hollow structures. 
They revealed that the hollow carbon nanospheres with a thin shell and open framework could effectively expose active sites, thereby making fully use of the active $\mathrm{Fe}-\mathrm{N}-\mathrm{C}$ components.

Zhang et al. ${ }^{[113]}$ constructed a single-shell hollow N-doped carbon matrix (HCM) by the $\mathrm{SiO}_{2}$ template method to anchor isolated $\mathrm{Ni}$ atoms. The isolated $\mathrm{Ni}$ atoms coordinate with the surrounding $\mathrm{N}$ atoms and the synergistic effect of Ni-N coordination can reduce $\mathrm{E}_{\mathrm{F}}$ and the adsorption energy of intermediates, which is essential for promoting the OER kinetics in alkaline conditions ${ }^{[113]}$. In order to study the correlation between $\mathrm{Ni}-\mathrm{N}_{x}$ geometry and $\mathrm{CO}_{2} \mathrm{RR}$ performance, Xiong et al. ${ }^{[114]}$ used $\mathrm{SiO}_{2}$ as a hard template to construct a series of Ni- $\mathrm{N}_{4}$ catalysts on carbon spheres with different geometric structures. They conducted an indepth study of the geometric parameters of the carbon support for the first time. The ultra-thin carbon shell changes the electronic structure of the carbon skeleton. By optimizing the carbon geometry, they obtained an ultra-thin carbon shell Ni/HMCS-3-800 with a higher pyrrole-N content and larger structural defects, which are conducive to $\mathrm{CO}_{2}$ activation. Simultaneously, mesopores (7-10 nm) have also been proved to be beneficial to $\mathrm{CO}_{2}$ transfer and adsorption. Thus, the geometry plays a key role in the $\mathrm{RDS}^{[114]}$.

Qiu et al. ${ }^{[115]}$ discovered the influence of the dimensionality of the graphene matrix on the formation of Fe SACs [Figure 5]. They revealed that single-shell hollow graphene spheres play a critical role in the preparation of single Fe atom catalysts. Due to the accumulation and aggregation of two-dimensional (2D) GO during the pyrolysis process, its surface area is reduced, single atomic sites are buried and mass transfer is blocked. Meanwhile, the FePc-immobilized 2D GO usually causes sintering and the aggregation of particles during pyrolysis, which has a negative impact on catalysis. In order to overcome these difficulties, single-shell hollow three-dimensional graphene spheres are used as scaffolds to immobilize Fe SACs (Fe ISAs/GHSs). The combination of single-atom Fe active sites and highly stable hollow structures endows Fe ISAs/GHSs with excellent ORR performance and improved activity and stability that are better than for most advanced commercial Pt/C catalysts. Li et al. ${ }^{[116]}$ used silica spheres as hard templates to fabricate Co SACs anchored in single-shell hollow carbon spheres (CoSAs-NHCS). The Co atoms were uniformly dispersed on the NHCS and coordinated with $\mathrm{N}$ to construct Co-N-C active sites. The high surface area of CoSAs-NHCS can expose more active sites and promote mass and electron transport. The single-shell structure of CoSAs-NHCS not only lowers the reaction barrier but also contains more discharge products.

The hard template method often complicates the process of making hollow structures. According to the self-template method reported by Liang et al ${ }^{[117]}$, single-shell hollow spheres with a single Fe atom were fabricated. The single-shell hollow structures increase the exposure of $\mathrm{Fe}-\mathrm{N}_{4}$ active sites, which show excellent ORR performance. Theoretical calculations combined with experiments revealed that $\mathrm{Fe} / \mathrm{NC}(\mathrm{PS})$ has outstanding ORR catalytic performance due to the low reaction barrier, adjustable electronic structure and suitable adsorption energy in $\mathrm{Fe}-\mathrm{N}_{4}$ active sites. In addition, Zhang et al. ${ }^{[118]}$ presented an efficient strategy to fabricate various SACs on single-shell hollow structured carbon. In this strategy, metal hydroxides or oxides [such as $\mathrm{Co}(\mathrm{OH})_{2}$ nanoplates, $\mathrm{MnO}_{2}$ nanowires and $\mathrm{NiFe}_{2} \mathrm{O}_{4} \mathrm{NPs}$ ] are first wrapped with polymers, pyrolyzed and acid leached at high temperature and then SACs are immobilized on the internal wall of the single-shell hollow pipe. Zhao et al. ${ }^{[119]}$ reported a urea-bridging strategy to prepare $\mathrm{N}$ doped hollow carbon tubes to anchor SACs (EA-SA). The results show that the atomically dispersed SACs on hollow carbon tubes are beneficial for increasing the exposed active sites and the transport of relevant species. These structural features endow EA-SAs with excellent ORR and OER activity. It is significant to fabricate heteroatom-doped metal tannic acid coordination materials with controllable morphology and stable chemical structures. Wei et al. ${ }^{[120]}$ proposed a template-free strategy to prepare cross-linked polyphosphazene hollow nanospheres. After pyrolysis, they constructed single metal atoms on N/P-doped mesoporous carbon nanospheres with a high surface area $\left(411.60 \mathrm{~m}^{2} \mathrm{~g}^{-1}\right)$. They showed the importance of 


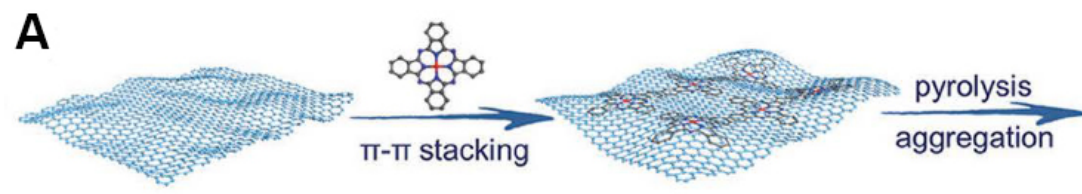

GO nanosheet
FePc/GO nanosheet

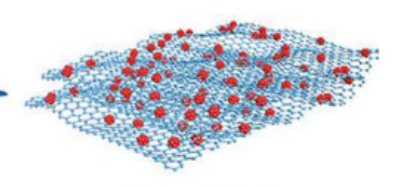

Fe-Nx/GNSs

B
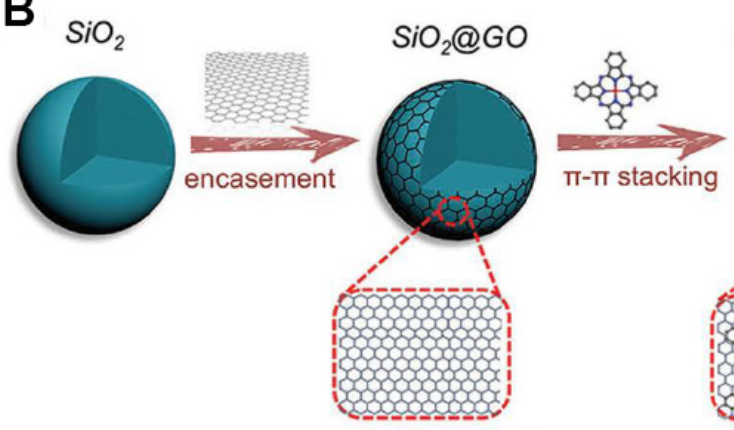

$\mathrm{SiO}_{2} @ G \mathrm{GO} / \mathrm{FePc}$
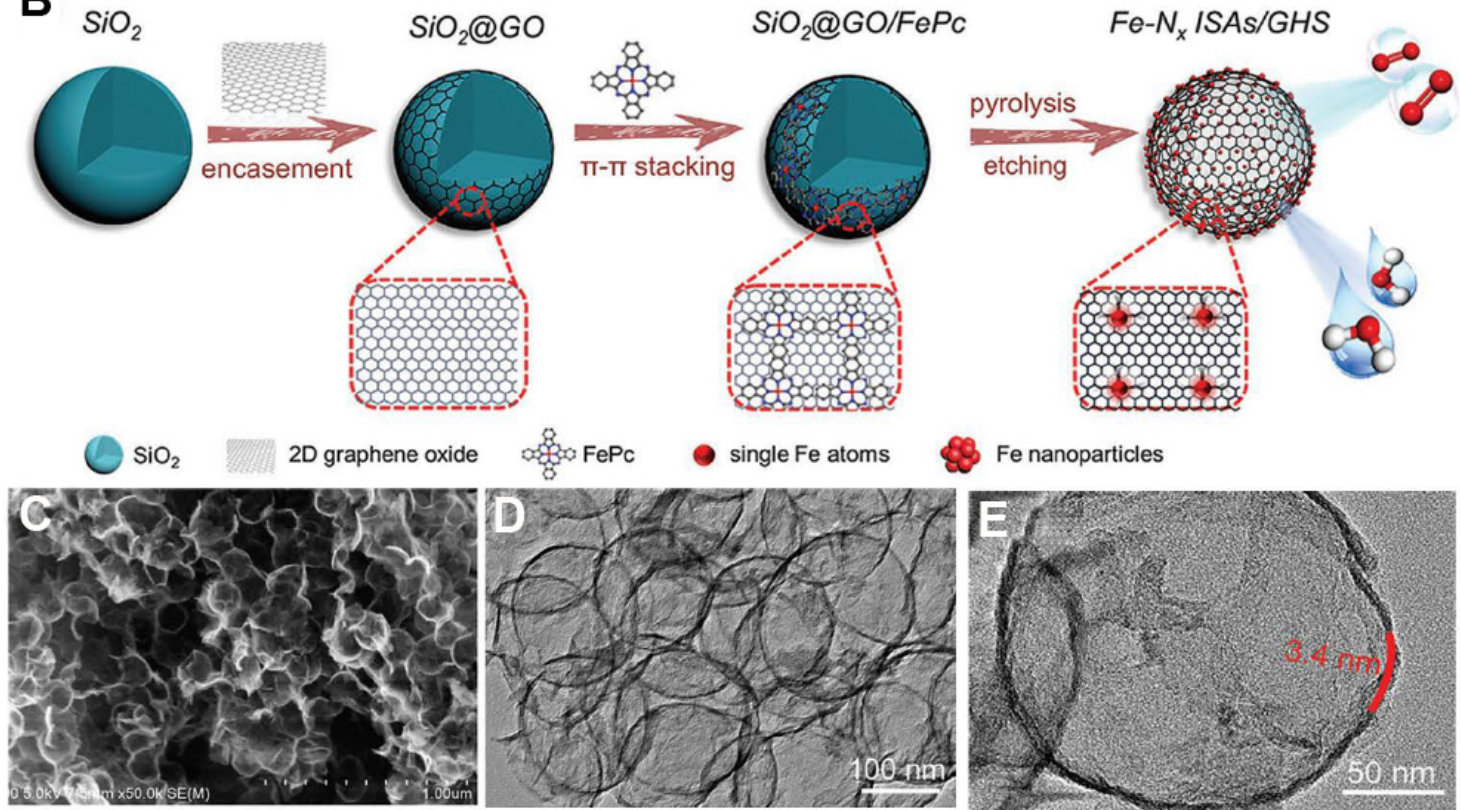

Fe nanoparticles
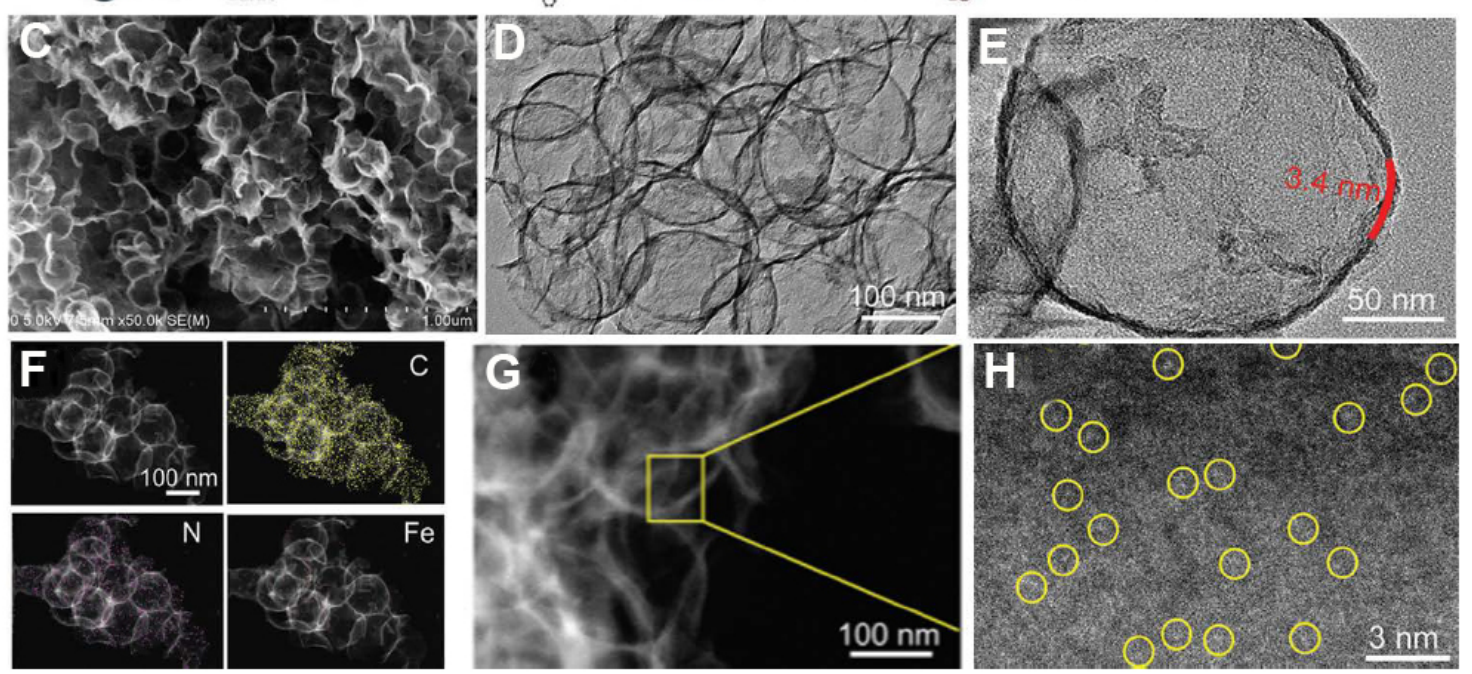

Figure 5. (A, B) Schematic illustration of the formation of Fe single atoms. (C) SEM, (D) TEM, (E) HRTEM, (F) elemental mapping and $(G, H)$ AC-HAADF-STEM images of Fe-N $\mathrm{N}_{\mathrm{x}}$ ISAs/GHSs. TEM: Transmission electron microscopy; HRTEM: high resolution TEM; ACHAADF-STEM: aberration-corrected high angle annular dark field scanning transmission electron microscopy.

mesoporous hollow structures and well-dispersed single Co atoms $\left(\mathrm{Co}-\mathrm{N}_{2} \mathrm{P}_{2}\right)$ through controlled experiments. The Co- $\mathrm{N}_{2} \mathrm{P}_{2}$ catalysts exhibited excellent electrocatalytic ORR activity, durability and methanol tolerance.

\section{SACs supported on core-shell materials}

Core-shell structures are composite materials where a solid core is directly coated with a different composition (shell). Therefore, core-shell structures can combine the characteristics of the core and the shell, rather than the single function of an individual NP. For instance, Hai et al ${ }^{[121]}$ reported a synthetic route to prepare a core-shell structured Co-SAC by pyrolysis of core-shell structured zeolitic imidazolate frameworks. The Co- $\mathrm{N}_{3} \mathrm{C}_{1} @ \mathrm{GC}$ possessed a high density of Co- $\mathrm{N}_{3} \mathrm{C}_{1}$ active sites in $\mathrm{N}$-doped microporous carbon, which were coated by a mesoporous carbon (shell) [Figure 6]. The catalysts showed excellent ORR performance and high stability (5000 cycles). Due to the reasonable design of the core-shell Co- $\mathrm{N}_{3} \mathrm{C}_{1} @ \mathrm{GC}$ catalysts, the thermodynamic and kinetic constraints can be overcome to achieve high-efficiency 


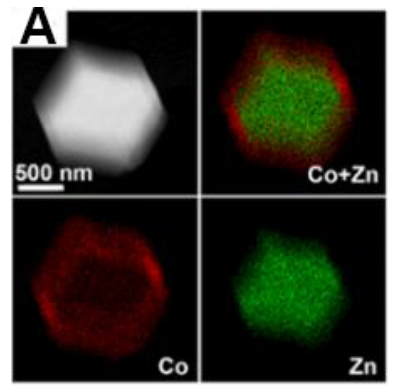

$\mathbf{E}$

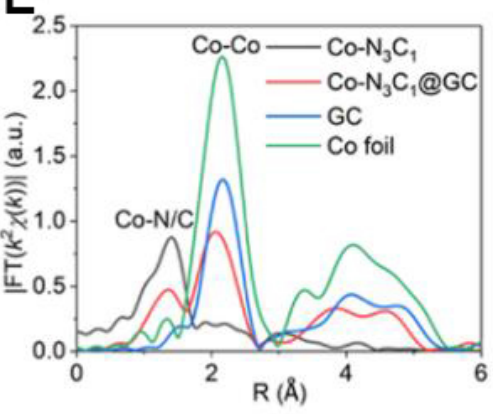

H

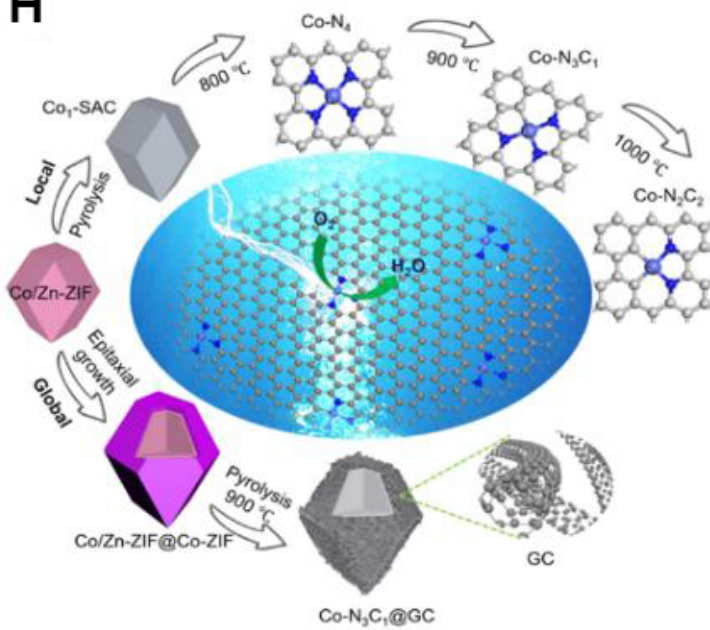

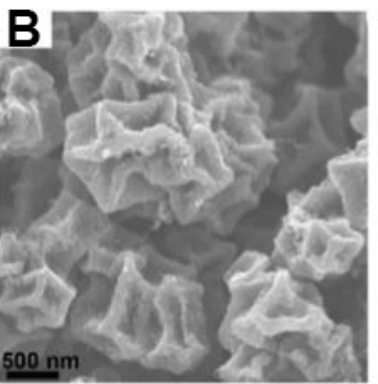

$\mathbf{F}$

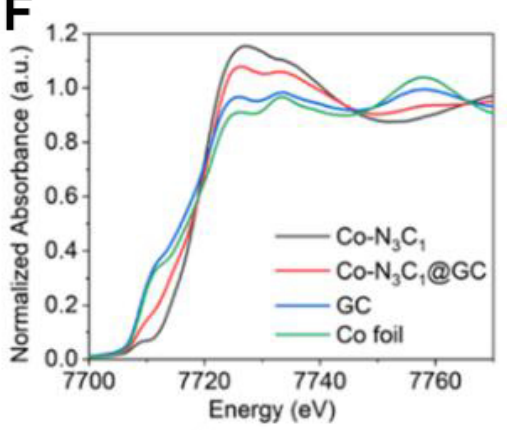

1
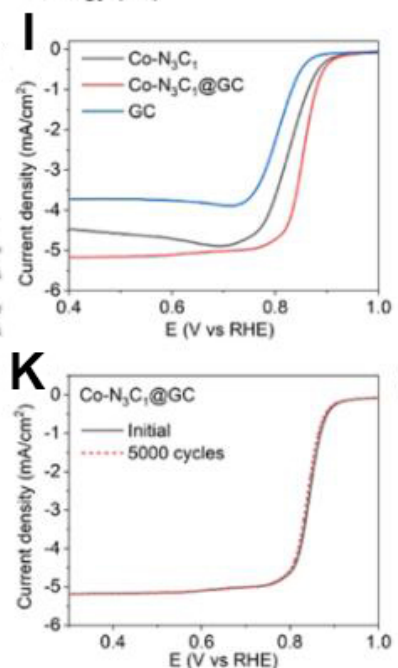

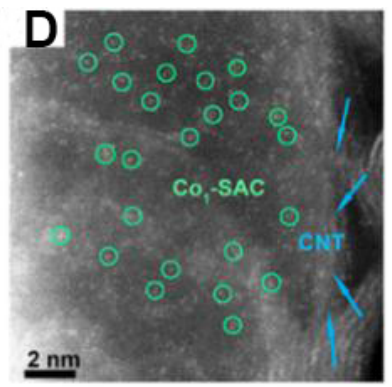

G

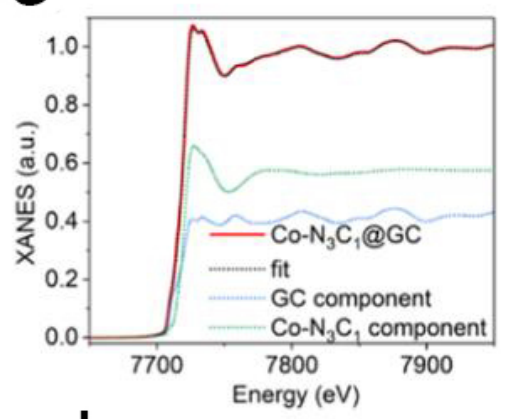

$\mathbf{J}$
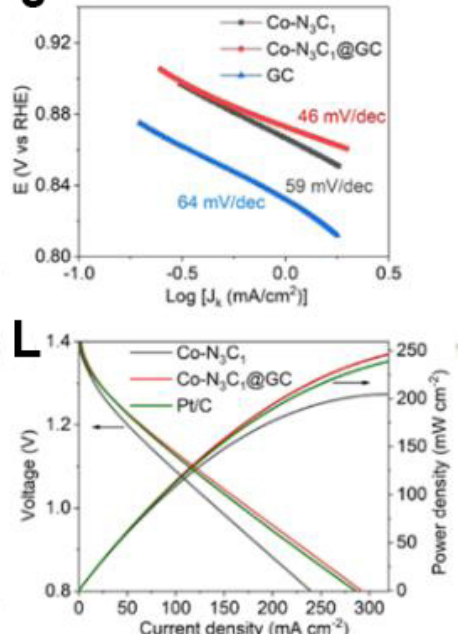

Figure 6. (A) STEM-EDS elemental mapping of core-shell Co/Zn-ZIF@ZIF-67. (B) SEM, (C) TEM and (D) AC STEM images of coreshell Co- $\mathrm{N}_{3} \mathrm{C}_{1} @ G C$. Co K-edge (E) FT-EXAFS, (F) XANES and (G) the corresponding XANES fitting curves of Co- $\mathrm{N}_{3} \mathrm{C}_{1} @ G \mathrm{G}$ and reference samples. (H) Schematic illustration of the formation of Co- $\mathrm{N}_{3} \mathrm{C}_{1} @ G C$. (I) LSV curves, (J) Tafel plots and (K) LSV curves before and after 5000 cycles of $\mathrm{Co}_{\mathrm{N}} \mathrm{N}_{3} \mathrm{C}_{1} @ \mathrm{GC}$. (L) A polarization curve of the battery and corresponding power density plot ${ }^{[121]}$. EDS: Energy-dispersive spectroscopy. EDS: Energy-dispersive spectroscopy; STEM: scanning transmission electron microscopy; AC STEM: aberration-corrected scanning transmission electron microscopy; FT-EXAFS: fourier transforms extended X-ray absorption fine structure; XANES: X-ray absorption near edge structure; LSV: linear sweep voltammetry.

performance. Compared with Co- $\mathrm{N}_{2} \mathrm{C}_{2}$ and $\mathrm{Co}-\mathrm{N}_{4}$, the Co- $\mathrm{N}_{3} \mathrm{C}_{1}$ promotes both the electronic hybridization with $\mathrm{O}_{2}$ and subsequent protonation of adsorbed $\mathrm{O}_{2}{ }^{*}$ to form $\mathrm{OOH}^{*}$. Co- $\mathrm{N}_{3} \mathrm{C}_{1}$ has a unique near-Fermi electronic structure before and after $\mathrm{O}_{2}$ adsorption, resulting in outstanding ORR performance. The Co- $\mathrm{N}_{3} \mathrm{C}_{1}$-SAC core-shell structures significantly improve the mass and electron transfer, thereby further enhancing the performance of the ORR and $\mathrm{Zn}$-air batteries. 
Song et al ${ }^{[86]}$ reported that single Fe atoms supported on a $2 \mathrm{D}$ carbon nanoplate (Fe/CNP) derived from $2 \mathrm{D}$ ZnO@Zn/Fe-ZIF show excellent ORR performance. The core-shell NiFe-LDH@Fe/CNP present stable ORR and OER performance. He et al. ${ }^{[122]}$ proposed a low-temperature CVD strategy to synthesize sheet-like open structures in which Ni NPs are coated by a Ni SAC supported carbon layer (Ni-NC@Ni) [Figure 7]. The obtained Ni-NC@Ni catalysts present high Faradaic efficiency $(\sim 87 \%)$ for $\mathrm{CO}_{2}$ electroreduction and significant current density $\left(14.8 \mathrm{~mA} \mathrm{~cm}^{-2}\right.$ at $\left.670 \mathrm{mV}\right)$, as well as stability $(150 \mathrm{~h})$. In addition, the core-shell structured Ni-NC@Ni promotes electron transport and mass transfer and the exposure of active site Ni-N species. Harzandi et al. ${ }^{[21]}$ proposed an efficient method for constructing the core-shell OER catalysts, in which metallic $\mathrm{Ru}$ (core) is coated with $\mathrm{RuO}_{x}$ (shell) supported Ni SACs. The obtained catalysts present outstanding activity $\left(10 \mathrm{~mA} \mathrm{~cm}{ }^{-2}\right.$ at a low overpotential of $\left.184 \mathrm{mV}\right)$ and stability $(\sim 200 \mathrm{~h})$ simultaneously in strong acidic media.

Pt SACs and bimetallic $\mathrm{Pt}_{3} \mathrm{Co}$ are considered the best ORR catalysts. Therefore, Lai et al. ${ }^{[123]}$ constructed sustainable quasi-Pt-allotrope catalysts, which consist of a $\mathrm{Pt}_{3} \mathrm{Co}$ alloy (cores) and $\mathrm{Pt}_{1} \mathrm{~N}$-C in $\mathrm{N}$-doped carbon (shells). The core-shell structure makes the internal and external spaces easy to access, thereby exposing a high active surface area and active sites. In addition, the novel $\mathrm{Pt}_{1} \mathrm{~N}-\mathrm{C}$ shells not only effectively protect the $\mathrm{H}-\mathrm{PtCo}$ cores from agglomeration but also improve the efficiency of the ORR with the help of Pt SACs. Thus, the core-shell H-PtCo@ $\mathrm{Pt}_{1} \mathrm{~N}-\mathrm{C}$ catalysts exhibit high stability (10000 cycles) in a $\mathrm{HClO}_{4}$ solution. They thoroughly studied the synergistic effect between the hollow structure of PtCo and single $\mathrm{Pt}$ atoms. Compared with H-PtCo@Pt ${ }_{1} \mathrm{~N}-\mathrm{C}$ catalysts, the ORR performance of ZIF-67-50-750 is reduced due to the deformation of the hollow structure and the agglomeration of single Pt atoms after high-temperature treatment. They revealed that the ultra-fine $\mathrm{Pt}_{3} \mathrm{Co}$ alloy (cores), $\mathrm{N}$-doped carbon (shells) and single $\mathrm{Pt}$ atoms synergistically endow $\mathrm{H}-\mathrm{PtCo} @ \mathrm{Pt}_{1} \mathrm{~N}-\mathrm{C}$ with enhanced ORR performance. First-principles calculations showed that the smaller the number of $\mathrm{N}$ atoms adjacent to $\mathrm{Pt}$, the smaller the corresponding overpotential, with $\mathrm{PtNC}_{3}$ being the most favorable atomic local environment. Cheng et al. ${ }^{[124]}$ demonstrated the synthesis of Co NPs (core) surrounded by N co-doped carbon nanofibers (shell) with Co SAC (Co@SACo-N-C). The core-shell Co@SACo-N-C presents outstanding ORR activity with an onset potential of $0.925 \mathrm{~V}$ and high stability in a $0.1 \mathrm{M} \mathrm{HClO}_{4}$ solution. The results strongly reveal that the introduction of Co NPs (core) makes the free energy diagrams on Co-N-C shell closer to the ideal case, thus improving the ORR performance.

\section{SACs supported on yolk-shell materials}

Due to the limited storage capacity provided by the core-shell structure, researchers are seeking superior designs and microstructural modifications for greater flexibility. Yolk-shell structures combine the high storage capacity of hollow structures and the advantages of core-shell structures and create voids between the external shell and internal core.

For example, Zhao et al. ${ }^{[79]}$ designed and constructed a yolk-shell biomimetic composite, in which $\mathrm{Fe}_{1}$ sites were atomically dispersed in a N-doped carbon shell and Pd SACs were anchored in a MOF-derived yolk. HAADF-STEM images show that the obtained yolk-shell $\mathrm{Pd}_{1} @ \mathrm{Fe}_{1}$ has an ultrathin carbon shell $(\sim 10 \mathrm{~nm})$ and an octahedral yolk derived from the MOF. This unique yolk-shell configuration may facilitate the exposure of catalytic sites and facilitate enhanced mass transfer during reactions. The Fe SACs strongly coordinate with four $\mathrm{N}$ atoms in the graphitic carbon shell. In addition, the corresponding fitting results show that both $\mathrm{Pd}$ and Fe have the same coordination number. Compared with $\mathrm{Pd}_{1}-\mathrm{N}_{4}$, the larger charge difference between the $\mathrm{Fe}$ and adjacent $\mathrm{N}$ atoms indicates that $\mathrm{Fe}_{1}-\mathrm{N}_{4}$ is more stable. This unique yolk-shell structure effectively regulates the spatial distribution of Pd and Fe SACs in one configuration, which can simultaneously activate molecular oxygen and hydrogen in the catalytic cycles without influence. By directly using the $\mathrm{O}_{2}$ and $\mathrm{H}_{2}$ produced by the electrocatalytic overall water splitting, the Fe SACs in the carbon shell and the Pd SACs in the yolk can simultaneously catalyze the hydrogenation of nitroaromatic hydrocarbons 

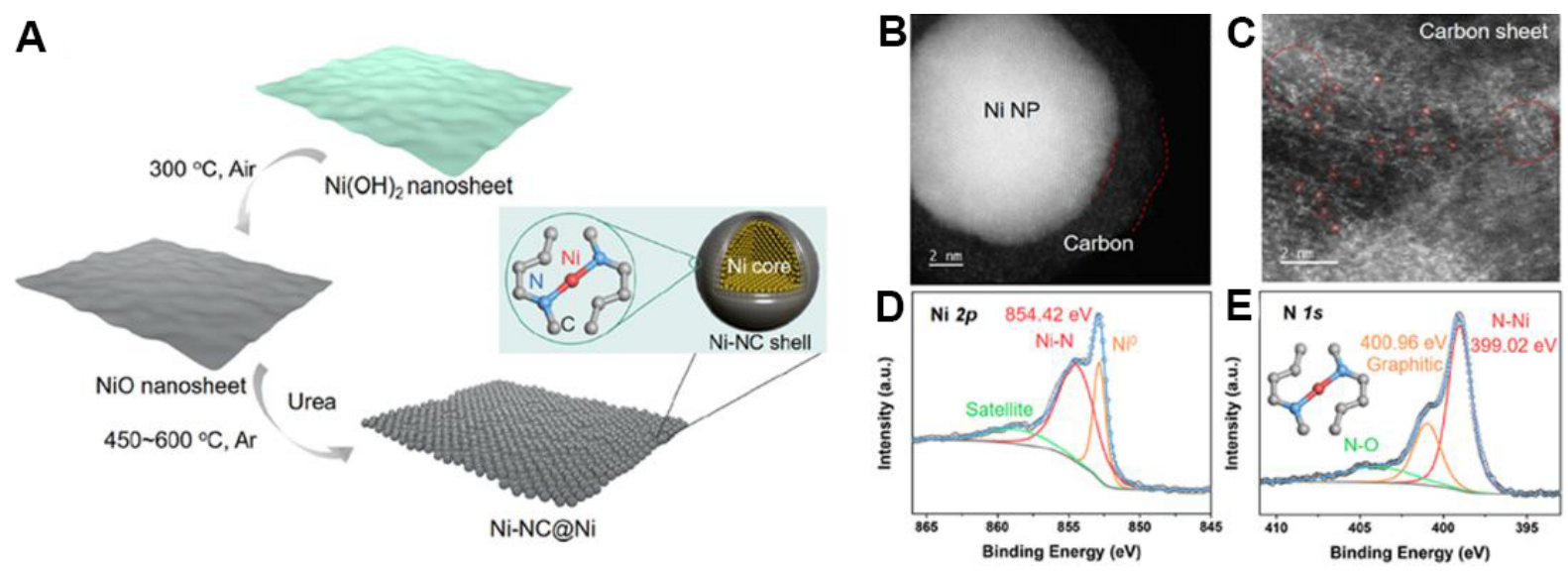

Figure 7. (A) Schematic illustration of the formation of Ni-NC@Ni. (B) HAADF-STEM and (C) AC HAADF-STEM images of Ni-NC@Ni. (D) High-resolution Ni 2p and (E) N 1s XPS spectra of Ni-NC@Ni (inset: atomic structure) ${ }^{[122]}$. AC HAADF-STEM: Aberration-corrected high angle annular dark field scanning transmission electron microscopy.

and the epoxidation of olefins, which leads to the cascade formation of amino alcohols. The void-free coreshell $\mathrm{Pd}_{1} @ \mathrm{Fe}_{1}(21 \%)$, yolk-shell $\mathrm{Fe}_{1} @ \mathrm{Pd}_{1}(4.9 \%)$ and hollow $\mathrm{Pd}_{1} @ \mathrm{Fe}_{1}(28 \%)$ exhibit weak chemoselectivity for 1-phenyl-2-(phenylamino) ethanol, which shows that the void and distribution order of the Pd and Fe SACs can synergistically accelerate the subsequent epoxide ring-opening amination reaction of the intermediate product.

Cai et al. ${ }^{[125]}$ proposed an effective strategy where Au yolks can diffuse into and even be atomically dispersed in the $\mathrm{Ni}_{2} \mathrm{P}$ shell by simple pyrolysis of the yolk-shell Au@Ni ${ }_{2} \mathrm{P}$ [Figure 8]. In-situ STEM shows the atomic diffusion of $\mathrm{Au}$ yolks and single-atom formation in the $\mathrm{Ni}_{2} \mathrm{P}$ shell. The obtained $\mathrm{Au}-\mathrm{Ni}_{2} \mathrm{P}$ samples showed significantly improved OER performance, which was 16 times higher than that of a commercial $\mathrm{IrO}_{2}$ sample. They revealed that the active sites originate from the synergy between $\mathrm{Au}$ SACs and the $\mathrm{Ni}_{2} \mathrm{P}$ shell. In addition, the $\mathrm{Au}-\mathrm{Ni}_{2} \mathrm{P}$ samples may cause changes in electronic structure, which also enhance OER performance.

There is a significant need for efficient dual-function catalysts to accelerate the ORR and OER. Furthermore, interfacial adjustment also improves the activity of catalysts. For example, Gao et al. ${ }^{[126]}$ reported a synchronous reduction method to prepare yolk-shell $\mathrm{Co}_{3} \mathrm{O}_{4} @ \mathrm{Co}_{3} \mathrm{O}_{4} / \mathrm{Ag}$ catalysts. Due to the synergistic interaction, the obtained $\mathrm{Co}_{3} \mathrm{O}_{4} @ \mathrm{Co}_{3} \mathrm{O}_{4} / \mathrm{Ag}$ shows a high initial capacity $\left(12000 \mathrm{mAh} \mathrm{g} \mathrm{g}^{-1}\right.$ at $\left.200 \mathrm{~mA} \mathrm{~g}^{-1}\right)$, high rate capability ( $4700 \mathrm{mAh} \mathrm{g}^{-1}$ at $\left.800 \mathrm{~mA} \mathrm{~g}^{-1}\right)$, low overpotential and long cycle life. The atomically dispersed $\mathrm{Ag}$ on the $\mathrm{Co}_{3} \mathrm{O}_{4}$ shell not only strengthens the $\mathrm{Ag} / \mathrm{Co}_{3} \mathrm{O}_{4}$ interfacial binding but also adjusts the valence electronic structure of $\mathrm{Ag}$ and Co species and improves the electronic conductivity. The yolk-shell structure offers more active sites for the ORR and OER and also improves the catalytic activity.

\section{CONCLUSIONS}

Due to their maximum utilization of metal atoms and unique electronic/coordination structures, SACs supported on microstructures have attracted significant attention in the field of energy conversion. The catalytic properties of SACs rely on the characteristics of the active sites and their accessibility to reactants, which are greatly affected by hollow microstructures. In this review, we have summarized recent process regarding SACs supported on hollow microstructures, including single-shell hollow, core-shell and yolkshell structures, and their application in energy conversion. First, we showed the inherent characteristics of $\mathrm{SAC}$ related to the hollow microstructures. Due to the unique hollow microstructures, most of the active 

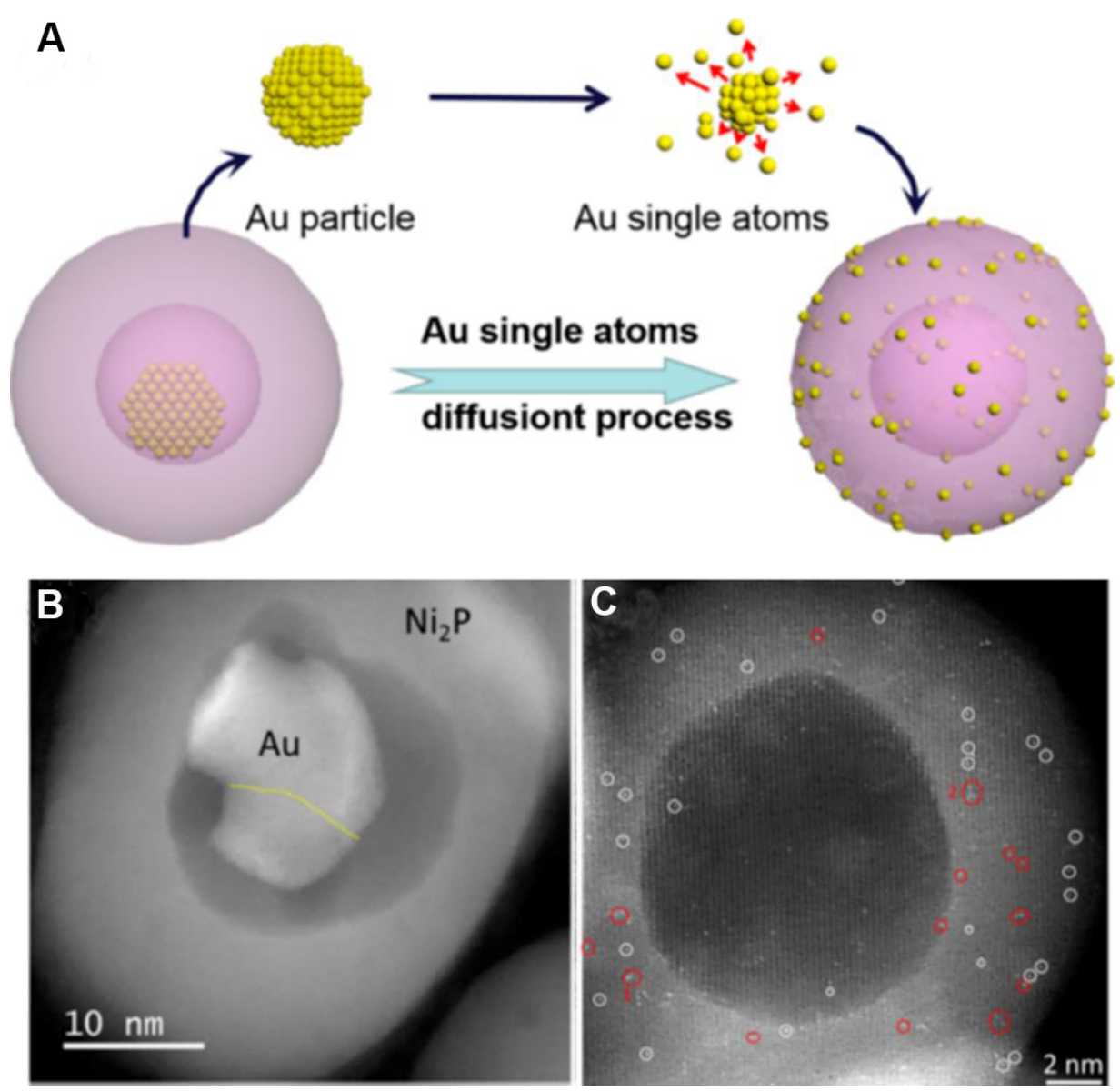

Figure 8. (A) Schematic illustration of the formation of Au-Ni 2 P. (B) HAADF-STEM and (C) AC HAADF-STEM images of Au-Ni ${ }_{2} P^{[125]}$. AC HAADF-STEM: Aberration-corrected high angle annular dark field scanning transmission electron microscopy.

sites can be exposed during the actual catalysis process. Compared with the bulk supports, the atomic utilization rate is truly improved. In addition, the interaction between SACs and hollow microstructured supports brings about unpredictable characteristics. This means that hollow microstructured supports cannot only adjust the geometry and electronic structure of SACs to improve activity but SACs can also serve as an auxiliary stimulus to the intrinsic activity of support to achieve better performance. The local and global structure of SAC-NC can profoundly affect the electrocatalytic performance. In addition, it has been proved that the geometric factors of the hollow carbon support (shell thickness, compactness and pore size) affect the electrocatalytic performance. How to design isolated atom pairs through effective strategies while avoiding the coexistence of a large number of atoms is a challenge. Compared with the reported traditional dual atomic catalysts, hollow microstructures are conducive to the isolation of atomically dispersed binary atom active sites on both sides of the shell.

However, despite the great progress made in the past few decades, there are still some challenges that need to be solved urgently. Herein, we have described some challenges of SACs supported on hollow structures to demonstrate the necessary via microstructure regulation. Hollow structured materials usually have a large specific surface area but how to increase the loading of a single atom to make full use of the surface area is still a great challenge. The hard template method often complicates the process of making hollow structures. In addition, the microenvironment of SACs is complex and flexible, and the electronic structure and coordination environment of the metal active sites are also dynamically evolving during the catalytic 
process, which makes the variability of the microstructure and the complexity of the catalytic reaction mechanism. Simplifying the synthesis steps of hollow structures is another critical challenge. From a synthesis perspective, precise control and manipulation of highly complex hollow structures remains challenging. It is generally accepted that more complex target structures usually require more complex synthesis procedures. The ultimate goal of SAC is to be used in industry. However, the particularity and complexity of hollow microstructures may make it difficult for SACs to achieve industrial applications. In addition, the cost and complexity of the catalyst is another factor that should be considered. These problems make the real application of SACs/2DM still have a long way to go, and more efforts are needed to solve these problems as soon as possible. Ensuring and identifying the uniformity of actual active sites are very important for the study of catalytic properties but are also challenging issues. Due to the harsh synthesis conditions and interference in the hollow microstructured supports, the coordination structure of the real active site may be diverse, which is not conducive to exploring the real structure-performance relationship. Furthermore, adjusting the thickness of the shell is a key method to adjust the catalytic performance.

We expect that the application of SACs supported on hollow microstructures will continue to expand in electrocatalysis. In the future, SACs will be able to effectively solve actual energy and environmental problems.

\section{DECLARATIONS}

\section{Authors' contributions}

Made the literature review and drafted the original version: Zhou AW

Revised the manuscript: Zhou AW, Wang DS

Conceived and supervised the project: Wang DS, Li YD

\section{Availability of data and materials}

Not applicable.

\section{Financial support and sponsorship}

This work was supported by Science and Technology Key Project of Guangdong Province of China (No. 2020B010188002), the National Key R\&D Program of China (2018YFA0702003), and the National Natural Science Foundation of China (Nos. 21890383, 21871159).

\section{Conflicts of interest}

All authors declared that there are no conflicts of interest.

\section{Ethical approval and consent to participate}

Not applicable.

\section{Consent for publication}

Not applicable.

\section{Copyright}

(c) The Author(s) 2022.

\section{REFERENCES}

1. Chen Z, Zhang X, Liu W, et al. Amination strategy to boost the $\mathrm{CO}_{2}$ electroreduction current density of M-N/C single-atom catalysts to the industrial application level. Energy Environ Sci 2021;14:2349-56. DOI

2. Zhou A, Dou Y, Zhao C, Zhou J, Wu X, Li J. A leaf-branch TiO2/carbon@MOF composite for selective $\mathrm{CO}_{2}$ photoreduction. Appl Catal B: Environ 2020;264:118519. DOI

3. Gao P, $\mathrm{Li} \mathrm{S}, \mathrm{Bu}$ X, et al. Direct conversion of $\mathrm{CO}_{2}$ into liquid fuels with high selectivity over a bifunctional catalyst. Nat Chem 


\section{7;9:1019-24. DOI PubMed}

4. Gabardo CM, O'brien CP, Edwards JP, et al. Continuous carbon dioxide electroreduction to concentrated multi-carbon products using a membrane electrode assembly. Joule 2019;3:2777-91. DOI

5. Dou Y, Zhou A, Yao Y, Lim SY, Li J, Zhang W. Suppressing hydrogen evolution for high selective $\mathrm{CO}_{2}$ reduction through surfacereconstructed heterojunction photocatalyst. Appl Catal B: Environ 2021;286:119876. DOI

6. Zhao C, Zhou A, Dou Y, Zhou J, Bai J, Li J. Dual MOFs template-directed fabrication of hollow-structured heterojunction photocatalysts for efficient $\mathrm{CO}_{2}$ reduction. Chem Eng $J$ 2021;416:129155. DOI

7. Zhang N, Ye C, Yan H, et al. Single-atom site catalysts for environmental catalysis. Nano Res 2020;13:3165-82. DOI

8. Ou H, Chen X, Lin L, Fang Y, Wang X. Biomimetic donor-acceptor motifs in conjugated polymers for promoting exciton splitting and charge separation. Angew Chem Int Ed Engl 2018;57:8729-33. DOI PubMed

9. Ou H, Tang C, Chen X, Zhou M, Wang X. Solvated electrons for photochemistry syntheses using conjugated carbon nitride polymers. ACS Catal 2019;9:2949-55. DOI

10. Xu Q, Zhang J, Wang D, Li Y. Single-atom site catalysts supported on two-dimensional materials for energy applications. Chin Chem Lett 2021. DOI

11. Ou H, Wang D, Li Y. How to select effective electrocatalysts: nano or single atom? Nano Select 2021;2:492-511. DOI

12. Gu J, Hsu CS, Bai L, Chen HM, Hu X. Atomically dispersed $\mathrm{Fe}^{3+}$ sites catalyze efficient $\mathrm{CO}_{2}$ electroreduction to CO. Science 2019;364:1091-4. DOI PubMed

13. Askins EJ, Zoric MR, Li M, Luo Z, Amine K, Glusac KD. Toward a mechanistic understanding of electrocatalytic nanocarbon. Nat Commun 2021;12:3288. DOI PubMed PMC

14. Zhu Y, Yang X, Peng C, Priest C, Mei Y, Wu G. Carbon-supported single metal site catalysts for electrochemical $\mathrm{CO}_{2}$ reduction to CO and beyond. Small 2021;17:e2005148. DOI PubMed

15. Zhang Y, Jiao L, Yang W, Xie C, Jiang HL. Rational fabrication of low-coordinate single-atom Ni electrocatalysts by MOFs for highly selective $\mathrm{CO}_{2}$ reduction. Angew Chem Int Ed Engl 2021;60:7607-11. DOI PubMed

16. Zhang $\mathrm{H}$, Cheng W, Luan D, Lou XWD. Atomically dispersed reactive centers for electrocatalytic $\mathrm{CO}_{2}$ reduction and water splitting. Angew Chem Int Ed Engl 2021;60:13177-96. DOI PubMed PMC

17. Chen $\mathrm{S}$, Wang B, Zhu J, et al. Lewis acid site-promoted single-atomic $\mathrm{Cu}$ catalyzes electrochemical $\mathrm{CO}_{2}$ methanation. Nano Lett 2021;21:7325-31. DOI PubMed

18. Zhou A, Liu X, Dou Y, Guan S, Han J, Wei M. The fabrication of oriented organic-inorganic ultrathin films with enhanced electrochromic properties. J Mater Chem C 2016;4:8284-90. DOI

19. Sultan S, Tiwari JN, Singh AN, et al. Single atoms and clusters based nanomaterials for hydrogen evolution, oxygen evolution reactions, and full water splitting. Adv Energy Mater 2019;9:1900624. DOI

20. Gusmão R, Veselý M, Sofer Z. Recent developments on the single atom supported at 2D materials beyond graphene as catalysts. ACS Catal 2020;10:9634-48. DOI

21. Harzandi AM, Shadman S, Nissimagoudar AS, et al. Ruthenium core-shell engineering with nickel single atoms for selective oxygen evolution via nondestructive mechanism. Adv Energy Mater 2021;11:2003448. DOI

22. Wang Y, Wang D, Li Y. Atom-level interfacial synergy of single-atom site catalysts for electrocatalysis. J Energy Chem 2022;65:103-15. DOI

23. Jing H, Liu W, Zhao Z, et al. Electronics and coordination engineering of atomic cobalt trapped by oxygen-driven defects for efficient cathode in solar cells. Nano Energy 2021;89:106365. DOI

24. Sun X, Tuo Y, Ye C, et al. Phosphorus induced electron localization of single iron sites for boosted $\mathrm{CO}_{2}$ electroreduction reaction. Angew Chem Int Ed Engl 2021;60:23614-8. DOI PubMed

25. Zhou A, Dou Y, Zhou J, Li JR. Rational localization of metal nanoparticles in yolk-shell MOFs for enhancing catalytic performance in selective hydrogenation of cinnamaldehyde. ChemSusChem 2020;13:205-11. DOI PubMed

26. Ryoo R, Kim J, Jo C, et al. Rare-earth-platinum alloy nanoparticles in mesoporous zeolite for catalysis. Nature 2020;585:221-4. DOI PubMed

27. Kim S, Jee S, Choi KM, Shin D. Single-atom Pd catalyst anchored on Zr-based metal-organic polyhedra for Suzuki-Miyaura cross coupling reactions in aqueous media. Nano Res 2021;14:486-92. DOI

28. He T, Kong XJ, Zhou J, et al. A practice of reticular chemistry: construction of a robust mesoporous palladium metal-organic framework via metal metathesis. J Am Chem Soc 2021;143:9901-11. DOI PubMed

29. Mao J, Li J, Pei J, Liu Y, Wang D, Li Y. Structure regulation of noble-metal-based nanomaterials at an atomic level. Nano Today 2019;26:164-75. DOI

30. Zhuang Z, Kang Q, Wang D, Li Y. Single-atom catalysis enables long-life, high-energy lithium-sulfur batteries. Nano Res 2020;13:1856-66. DOI

31. Zhou A, Guo R, Zhou J, Dou Y, Chen Y, Li J. Pd@ZIF-67 derived recyclable Pd-based catalysts with hierarchical pores for highperformance heck reaction. ACS Sustainable Chem Eng 2018;6:2103-11. DOI

32. Wang X, Feng J, Bai Y, Zhang Q, Yin Y. Synthesis, properties, and applications of hollow micro-/nanostructures. Chem Rev 2016;116:10983-1060. DOI PubMed

33. Prieto G, Tüysüz H, Duyckaerts N, Knossalla J, Wang GH, Schüth F. Hollow nano- and microstructures as catalysts. Chem Rev 2016;116:14056-119. DOI PubMed

34. Wang Z, Qi J, Yang N, Yu R, Wang D. Core-shell nano/microstructures for heterogeneous tandem catalysis. Mater Chem Front 2021;5:1126-39. DOI 
35. Zhao Z, Ge G, Li W, Guo X, Wang G. Modulating the microstructure and surface chemistry of carbocatalysts for oxidative and direct dehydrogenation: a review. Chin J Catal 2016;37:644-70. DOI

36. Zhu C, Fu S, Shi Q, Du D, Lin Y. Single-atom electrocatalysts. Angew Chem Int Ed Engl 2017;56:13944-60. DOI PubMed

37. Li Z, Ji S, Liu Y, et al. Well-defined materials for heterogeneous catalysis: from nanoparticles to isolated single-atom sites. Chem Rev 2020;120:623-82. DOI PubMed

38. Meng G, Zhang J, Li X, Wang D, Li Y. Electronic structure regulations of single-atom site catalysts and their effects on the electrocatalytic performances. Appl Phys Rev 2021;8:021321. DOI

39. Qiao B, Wang A, Yang X, et al. Single-atom catalysis of CO oxidation using Pt1/FeOx. Nat Chem 2011;3:634-41. DOI PubMed

40. Zhuang Z, Li Y, Li Y, et al. Atomically dispersed nonmagnetic electron traps improve oxygen reduction activity of perovskite oxides. Energy Environ Sci 2021;14:1016-28. DOI

41. Xiong Y, Dong J, Huang ZQ, et al. Single-atom Rh/N-doped carbon electrocatalyst for formic acid oxidation. Nat Nanotechnol 2020;15:390-7. DOI PubMed

42. Wu Y, Wang D, Li Y. Nanocrystals from solutions: catalysts. Chem Soc Rev 2014;43:2112-24. DOI PubMed

43. Zhang J, Wang $\mathrm{Z}$, Chen $\mathrm{W}$, et al. Tuning polarity of $\mathrm{Cu}-\mathrm{O}$ bond in heterogeneous $\mathrm{Cu}$ catalyst to promote additive-free hydroboration of alkynes. Chem 2020;6:725-37. DOI

44. Li X, Rong H, Zhang J, Wang D, Li Y. Modulating the local coordination environment of single-atom catalysts for enhanced catalytic performance. Nano Res 2020;13:1842-55. DOI

45. Duchesne PN, Li ZY, Deming CP, et al. Golden single-atomic-site platinum electrocatalysts. Nat Mater 2018;17:1033-9. DOI PubMed

46. Fu N, Liang X, Li Z, et al. Fabricating Pd isolated single atom sites on C3N4/rGO for heterogenization of homogeneous catalysis. Nano Res 2020;13:947-51. DOI

47. Sun T, Xu L, Wang D, Li Y. Metal organic frameworks derived single atom catalysts for electrocatalytic energy conversion. Nano Res 2019;12:2067-80. DOI

48. Wei S, Li A, Liu JC, et al. Direct observation of noble metal nanoparticles transforming to thermally stable single atoms. Nat Nanotechnol 2018;13:856-61. DOI PubMed

49. Xu Q, Guo C, Tian S, et al. Coordination structure dominated performance of single-atomic Pt catalyst for anti-Markovnikov hydroboration of alkenes. Sci China Mater 2020;63:972-81. DOI

50. Wang Y, Chen Z, Shen R, et al. Pd-dispersed CuS hetero-nanoplates for selective hydrogenation of phenylacetylene. Nano Res 2016;9:1209-19. DOI

51. Zhang J, Zheng C, Zhang M, et al. Controlling N-doping type in carbon to boost single-atom site Cu catalyzed transfer hydrogenation of quinoline. Nano Res 2020;13:3082-7. DOI

52. Xiong Y, Sun W, Han Y, et al. Cobalt single atom site catalysts with ultrahigh metal loading for enhanced aerobic oxidation of ethylbenzene. Nano Res 2021;14:2418-23. DOI

53. Cui T, Ma L, Wang S, et al. Atomically dispersed Pt- $\mathrm{N}_{3} \mathrm{C}_{1}$ sites enabling efficient and selective electrocatalytic C-C bond cleavage in lignin models under ambient conditions. J Am Chem Soc 2021;143:9429-39. DOI PubMed

54. Han Y, Dai J, Xu R, et al. Notched-polyoxometalate strategy to fabricate atomically dispersed Ru catalysts for biomass conversion. ACS Catal 2021;11:2669-75. DOI

55. Maschmeyer T, Rey F, Sankar G, Thomas JM. Heterogeneous catalysts obtained by grafting metallocene complexes onto mesoporous silica. Nature 1995;378:159-62. DOI

56. Fu Q, Saltsburg H, Flytzani-Stephanopoulos M. Active nonmetallic Au and Pt species on ceria-based water-gas shift catalysts. Science 2003;301:935-8. DOI PubMed

57. Hackett SF, Brydson RM, Gass MH, et al. High-activity, single-site mesoporous Pd/A12O3 catalysts for selective aerobic oxidation of allylic alcohols. Angew Chem Int Ed Engl 2007;46:8593-6. DOI PubMed

58. Yin $\mathrm{P}, \mathrm{Yao} \mathrm{T}, \mathrm{Wu} \mathrm{Y}$, et al. Single cobalt atoms with precise N-coordination as superior oxygen reduction reaction catalysts. Angew Chem Int Ed Engl 2016;55:10800-5. DOI PubMed

59. Chen Y, Ji S, Chen C, Peng Q, Wang D, Li Y. Single-atom catalysts: synthetic strategies and electrochemical applications. Joule 2018;2:1242-64. DOI

60. Wang A, Li J, Zhang T. Heterogeneous single-atom catalysis. Nat Rev Chem 2018;2:65-81. DOI

61. Ji S, Qu Y, Wang T, et al. Rare-earth single erbium atoms for enhanced photocatalytic $\mathrm{CO}_{2}$ reduction. Angew Chem Int Ed Engl 2020;59:10651-7. DOI PubMed

62. Wang G, Huang R, Zhang J, Mao J, Wang D, Li Y. Synergistic modulation of the separation of photo-generated carries via engineering of dual atomic sites for promoting photocatalytic performance. Adv Mater 2021:e2105904. DOI PubMed

63. Li WH, Yang J, Jing H, et al. Creating high regioselectivity by electronic metal-support interaction of a single-atomic-site catalyst. $J$ Am Chem Soc 2021;143:15453-61. DOI PubMed

64. Liu Z, Du Y, Zhang P, Zhuang Z, Wang D. Bringing catalytic order out of chaos with nitrogen-doped ordered mesoporous carbon. Matter 2021;4:3161-94. DOI

65. Yang $\mathrm{T}$, Mao $\mathrm{X}$, Zhang $\mathrm{Y}$, et al. Coordination tailoring of $\mathrm{Cu}$ single sites on $\mathrm{C}_{3} \mathrm{~N}_{4}$ realizes selective $\mathrm{CO}_{2}$ hydrogenation at low temperature. Nat Commun 2021;12:6022. DOI PubMed PMC

66. Tang C, Jiao Y, Shi B, et al. Coordination tunes selectivity: two-electron oxygen reduction on high-loading molybdenum single-atom catalysts. Angew Chem Int Ed Engl 2020;59:9171-6. DOI PubMed

67. Wu K, Chen X, Liu S, et al. Porphyrin-like Fe- $\mathrm{N}_{4}$ sites with sulfur adjustment on hierarchical porous carbon for different rate- 
determining steps in oxygen reduction reaction. Nano Res 2018;11:6260-9. DOI

68. Jiao J, Lin R, Liu S, et al. Copper atom-pair catalyst anchored on alloy nanowires for selective and efficient electrochemical reduction of $\mathrm{CO}_{2}$. Nat Chem 2019;11:222-8. DOI PubMed

69. Han A, Zhang Z, Li X, Wang D, Li Y. Atomic thickness catalysts: synthesis and applications. Small Methods 2020;4:2000248. DOI

70. Wang Y, Wang D, Li Y. Rational design of single-atom site electrocatalysts: from theoretical understandings to practical applications. Adv Mater 2021;33:e2008151. DOI PubMed

71. Wang Y, Mao J, Meng X, Yu L, Deng D, Bao X. Catalysis with two-dimensional materials confining single atoms: concept, design, and applications. Chem Rev 2019;119:1806-54. DOI PubMed

72. Qi K, Chhowalla M, Voiry D. Single atom is not alone: metal-support interactions in single-atom catalysis. Mater Today 2020;40:173-92. DOI

73. Yang J, Li W, Wang D, Li Y. Electronic metal-support interaction of single-atom catalysts and applications in electrocatalysis. Adv Mater 2020;32:e2003300. DOI PubMed

74. Wang GH, Hilgert J, Richter FH, et al. Platinum-cobalt bimetallic nanoparticles in hollow carbon nanospheres for hydrogenolysis of 5-hydroxymethylfurfural. Nat Mater 2014;13:293-300. DOI PubMed

75. Yang J, Li W, Wang D, Li Y. Single-atom materials: small structures determine macroproperties. Small Structures 2021;2:2000051. DOI

76. Zhang Z, Zhou M, Chen Y, et al. Pd single-atom monolithic catalyst: functional 3D structure and unique chemical selectivity in hydrogenation reaction. Sci China Mater 2021;64:1919-29. DOI

77. Yang J, Li WH, Tan S, et al. The electronic metal-support interaction directing the design of single atomic site catalysts: achieving high efficiency towards hydrogen evolution. Angew Chem Int Ed Engl 2021;60:19085-91. DOI PubMed

78. Zhao J, Ji S, Guo C, et al. A heterogeneous iridium single-atom-site catalyst for highly regioselective carbenoid O-H bond insertion. Nat Catal 2021;4:523-31. DOI

79. Zhao Y, Zhou H, Zhu X, et al. Simultaneous oxidative and reductive reactions in one system by atomic design. Nat Catal 2021;4:13443. DOI

80. Zhang T, Han X, Yang H, et al. Atomically dispersed nickel(I) on an alloy-encapsulated nitrogen-doped carbon nanotube array for high-performance electrochemical $\mathrm{CO}_{2}$ reduction reaction. Angew Chem Int Ed Engl 2020;59:12055-61. DOI PubMed

81. Li Z, Wu HB, (David) Lou XW. Rational designs and engineering of hollow micro-/nanostructures as sulfur hosts for advanced lithium-sulfur batteries. Energy Environ Sci 2016;9:3061-70. DOI

82. Kumar R. $\mathrm{NiCO}_{2} \mathrm{O}_{4}$ nano-/microstructures as high-performance biosensors: a review. Nanomicro Lett 2020;12:122. DOI PubMed PMC

83. Yu J, Feng H, Tang L, et al. Metal-free carbon materials for persulfate-based advanced oxidation process: microstructure, property and tailoring. Prog Mater Sci 2020;111:100654. DOI

84. Yu L, Yu XY, Lou XWD. The design and synthesis of hollow micro-/nanostructures: present and future trends. Adv Mater 2018;30:e1800939. DOI PubMed

85. Wang Z, Jia W, Jiang M, Chen C, Li Y. One-step accurate synthesis of shell controllable $\mathrm{CoFe}_{2} \mathrm{O}_{4}$ hollow microspheres as highperformance electrode materials in supercapacitor. Nano Res 2016;9:2026-33. DOI

86. Song X, Chen S, Guo L, et al. General dimension-controlled synthesis of hollow carbon embedded with metal singe atoms or coreshell nanoparticles for energy storage applications. Adv Energy Mater 2018;8:1801101. DOI

87. Liu C, Bi Y, Han J, Guo M, Liu Q. A Perspective on the relationship between microstructure and performance of Cu-based zeolites for the selective catalytic reduction of $\mathrm{NO}_{\mathrm{x}}$. Catal Surv Asia 2020;24:179-95. DOI

88. Kong W, Tian B, Zhang J, He D, Anpo M. Microstructure and hydrogen production activity of Pt-TiO2 prepared by precipitationphotodeposition. Res Chem Intermed 2013;39:1701-10. DOI

89. Shojaeefard M, Molaeimanesh G, Nazemian M, Moqaddari M. A review on microstructure reconstruction of PEM fuel cells porous electrodes for pore scale simulation. Int J Hydrogen Energy 2016;41:20276-93. DOI

90. Yang D, Yu H, He T, et al. Visible-light-switched electron transfer over single porphyrin-metal atom center for highly selective electroreduction of carbon dioxide. Nat Commun 2019;10:3844. DOI PubMed PMC

91. Wang Z, Wang C, Hu Y, et al. Simultaneous diffusion of cation and anion to access N, S co-coordinated Bi-sites for enhanced $\mathrm{CO}_{2}$ electroreduction. Nano Res 2021;14:2790-6. DOI

92. Yuan C, Zhan L, Liu S, et al. Semi-sacrificial template synthesis of single-atom Ni sites supported on hollow carbon nanospheres for efficient and stable electrochemical $\mathrm{CO}_{2}$ reduction. Inorg Chem Front 2020;7:1719-25. DOI

93. Kim S, Lauterbach J, Sasmaz E. Yolk-shell Pt-NiCe@ $\mathrm{SiO}_{2}$ single-atom-alloy catalysts for low-temperature dry reforming of methane. ACS Catal 2021;11:8247-60. DOI

94. Chen Y, Ji S, Zhao S, et al. Enhanced oxygen reduction with single-atomic-site iron catalysts for a zinc-air battery and hydrogen-air fuel cell. Nat Commun 2018;9:5422. DOI PubMed PMC

95. Wei YS, Zhang M, Zou R, Xu Q. Metal-organic framework-based catalysts with single metal sites. Chem Rev 2020;120:12089-174. DOI PubMed

96. Hou C, Wang H, Li C, Xu Q. From metal-organic frameworks to single/dual-atom and cluster metal catalysts for energy applications. Energy Environ Sci 2020;13:1658-93. DOI

97. Song Z, Zhang L, Doyle-davis K, Fu X, Luo J, Sun X. Recent advances in MOF-derived single atom catalysts for electrochemical applications. Adv Energy Mater 2020;10:2001561. DOI

98. He T, Huang Z, Yuan S, et al. Kinetically controlled reticular assembly of a chemically stable mesoporous Ni(II)-pyrazolate metal- 
organic framework. J Am Chem Soc 2020;142:13491-9. DOI PubMed

99. Gong YN, Jiao L, Qian Y, et al. Regulating the coordination environment of MOF-templated single-atom nickel electrocatalysts for boosting $\mathrm{CO}_{2}$ reduction. Angew Chem Int Ed Engl 2020;59:2705-9. DOI PubMed

100. Liang Z, Qu C, Xia D, Zou R, Xu Q. Atomically dispersed metal sites in MOF-based materials for electrocatalytic and photocatalytic energy conversion. Angew Chem Int Ed Engl 2018;57:9604-33. DOI PubMed

101. Chen Y, Gao R, Ji S, et al. Atomic-level modulation of electronic density at cobalt single-atom sites derived from metal-organic frameworks: enhanced oxygen reduction performance. Angew Chem Int Ed Engl 2021;60:3212-21. DOI PubMed

102. He T, Chen S, Ni B, et al. Zirconium-porphyrin-based metal-organic framework hollow nanotubes for immobilization of noble-metal single atoms. Angew Chem Int Ed Engl 2018;57:3493-8. DOI PubMed

103. Yang Z, Wang X, Zhu M, et al. Structural revolution of atomically dispersed Mn sites dictates oxygen reduction performance. Nano Res 2021;14:4512-9. DOI

104. Wang C, Chen Y, Zhong M, et al. Hollow mesoporous carbon nanocages with Fe isolated single atomic site derived from a MOF/polymer for highly efficient electrocatalytic oxygen reduction. J Mater Chem A 2021;9:22095-101. DOI

105. Li Y, Zhang SL, Cheng W, et al. Loading single-Ni atoms on assembled hollow N-rich carbon plates for efficient $\mathrm{CO}_{2}$ Electroreduction. Adv Mater 2021:e2105204. DOI PubMed

106. Han A, Wang X, Tang K, et al. An adjacent atomic platinum site enables single-atom iron with high oxygen reduction reaction performance. Angew Chem Int Ed Engl 2021;60:19262-71. DOI PubMed

107. Han X, Ling X, Yu D, et al. Atomically dispersed binary Co-Ni sites in nitrogen-doped hollow carbon nanocubes for reversible oxygen reduction and evolution. Adv Mater 2019;31:e1905622. DOI PubMed

108. Deng $\mathrm{Y}$, Chi B, Tian X, et al. g- $\mathrm{C}_{3} \mathrm{~N}_{4}$ promoted MOF derived hollow carbon nanopolyhedra doped with high density/fraction of single Fe atoms as an ultra-high performance non-precious catalyst towards acidic ORR and PEM fuel cells. J Mater Chem A 2019;7:502030. DOI

109. Su P, Huang W, Zhang J, et al. Fe atoms anchored on defective nitrogen doped hollow carbon spheres as efficient electrocatalysts for oxygen reduction reaction. Nano Res 2021;14:1069-77. DOI

110. Kuang P, Wang Y, Zhu B, et al. Pt single atoms supported on N-doped mesoporous hollow carbon spheres with enhanced electrocatalytic $\mathrm{H}_{2}$-evolution activity. Adv Mater 2021;33:e2008599. DOI PubMed

111. Chen J, Li H, Fan C, et al. Dual single-atomic Ni- $\mathrm{N}_{4}$ and $\mathrm{Fe}-\mathrm{N}_{4}$ sites constructing janus hollow graphene for selective oxygen electrocatalysis. Adv Mater 2020;32:e2003134. DOI PubMed

112. Chen Y, Li Z, Zhu Y, et al. Atomic Fe dispersed on N-doped carbon hollow nanospheres for high-efficiency electrocatalytic oxygen reduction. Adv Mater 2019;31:e1806312. DOI PubMed

113. Zhang H, Liu Y, Chen T, Zhang J, Zhang J, Lou XWD. unveiling the activity origin of electrocatalytic oxygen evolution over isolated Ni atoms supported on a N-doped carbon matrix. Adv Mater 2019;31:e1904548. DOI PubMed

114. Xiong W, Li H, Wang $\mathrm{H}$, et al. Hollow mesoporous carbon sphere loaded Ni- $\mathrm{N}_{4}$ single-atom: support structure study for $\mathrm{CO}_{2}$ electrocatalytic reduction catalyst. Small 2020;16:e2003943. DOI PubMed

115. Qiu X, Yan X, Pang H, et al. Isolated Fe single atomic sites anchored on highly steady hollow graphene nanospheres as an efficient electrocatalyst for the oxygen reduction reaction. Adv Sci (Weinh) 2019;6:1801103. DOI PubMed PMC

116. Li D, Xu K, Zhu M, et al. Synergistic catalysis by single-atom catalysts and redox mediator to improve lithium-oxygen batteries performance. Small 2021;17:e2101620. DOI PubMed

117. Liang K, Yuan C, Zhou X, et al. Osmotic pressure-induced pocket-like spheres with Fe single-atom sites for the oxygen reduction reaction. J Mater Chem A 2021;9:13908-15. DOI

118. Zhang M, Wang YG, Chen W, et al. Metal (Hydr)oxides@Polymer core-shell strategy to metal single-atom materials. J Am Chem Soc 2017;139:10976-9. DOI PubMed

119. Zhao J, Qin R, Liu R. Urea-bridging synthesis of nitrogen-doped carbon tube supported single metallic atoms as bifunctional oxygen electrocatalyst for zinc-air battery. Appl Catal B Environ 2019;256:117778. DOI

120. Wei X, Zheng D, Zhao M, et al. Cross-linked polyphosphazene hollow nanosphere-derived N/P-doped porous carbon with single nonprecious metal atoms for the oxygen reduction reaction. Angew Chem Int Ed Engl 2020;59:14639-46. DOI PubMed

121. Hai X, Zhao X, Guo N, et al. Engineering local and global structures of single Co atoms for a superior oxygen reduction reaction. ACS Catal 2020;10:5862-70. DOI

122. He Y, Li Y, Zhang J, et al. Low-temperature strategy toward Ni-NC@Ni core-shell nanostructure with single-Ni sites for efficient $\mathrm{CO}_{2}$ electroreduction. Nano Energy 2020;77:105010. DOI

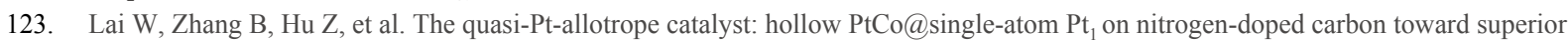
oxygen reduction. Adv Funct Mater 2019;29:1807340. DOI

124. Cheng Q, Han S, Mao K, et al. Co nanoparticle embedded in atomically-dispersed Co-N-C nanofibers for oxygen reduction with high activity and remarkable durability. Nano Energy 2018;52:485-93. DOI

125. Cai C, Han S, Wang Q, Gu M. Direct observation of yolk-shell transforming to gold single atoms and clusters with superior oxygen evolution reaction efficiency. ACS Nano 2019;13:8865-71. DOI PubMed

126. Gao R, Yang Z, Zheng L, et al. Enhancing the catalytic activity of $\mathrm{Co}_{3} \mathrm{O}_{4}$ for $\mathrm{Li}-\mathrm{O}_{2}$ batteries through the synergy of surface/interface/doping engineering. ACS Catal 2018;8:1955-63. DOI 